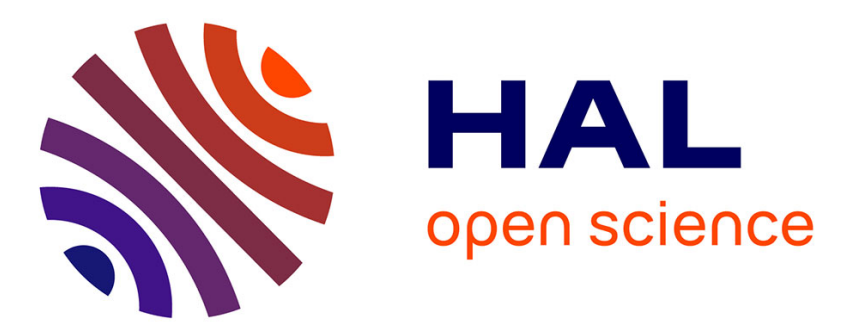

\title{
Diversity of receptive field changes in auditory cortex during natural sleep
}

Jean-Marc Edeline, Gérard Dutrieux, Yves Manunta, Elizabeth Hennevin

\section{To cite this version:}

Jean-Marc Edeline, Gérard Dutrieux, Yves Manunta, Elizabeth Hennevin. Diversity of receptive field changes in auditory cortex during natural sleep. European Journal of Neuroscience, 2001, 14 (11), pp.1865-80. 10.1046/j.0953-816x.2001.01821.x . hal-02397995

\section{HAL Id: hal-02397995 \\ https://hal.science/hal-02397995}

Submitted on 11 Dec 2019

HAL is a multi-disciplinary open access archive for the deposit and dissemination of scientific research documents, whether they are published or not. The documents may come from teaching and research institutions in France or abroad, or from public or private research centers.
L'archive ouverte pluridisciplinaire HAL, est destinée au dépôt et à la diffusion de documents scientifiques de niveau recherche, publiés ou non, émanant des établissements d'enseignement et de recherche français ou étrangers, des laboratoires publics ou privés. 


\title{
Diversity of receptive field changes in auditory cortex during natural sleep
}

\author{
Jean-Marc Edeline, Gérard Dutrieux, Yves Manunta and Elizabeth Hennevin \\ Laboratoire de Neurobiologie de l'Apprentissage, de la Mémoire et de la Communication, UMR CNRS 8620, Université Paris- \\ Sud, Bât. 446, 91405 Orsay cedex, France
}

Keywords: frequency tuning, guinea pig, single-unit recording, slow-wave sleep, wakefulness

\begin{abstract}
Twenty years ago, the study by Livingstone and Hubel [(1981) Nature, 291, 554] was viewed as a first step toward understanding how changes in state of vigilance affect sensory processing. Since then, however, very few attempts have been made to progress in this direction. In the present study, 56 cells were recorded in the auditory cortex of adult, undrugged guinea pigs, and the frequency tuning curves were tested during continuous and stable periods of wakefulness and of slow-wave sleep (SWS). Twelve cells were also tested during paradoxical sleep. Over the whole cell population, the reponse latency, the frequency selectivity and the size of the suprathreshold receptive field were not significantly modified during SWS compared with waking. However, this lack of global effects resulted from the heterogeneity of response changes displayed by cortical cells. During SWS, the receptive field size varied as a function of the changes in evoked responses: it was unchanged for the cells whose evoked responses were not modified (38\% of the cells), reduced for the cells whose responses were decreased (48\%) and enlarged for the cells whose responses were increased (14\%). This profile of changes differs from the prevalent receptive field shrinkage that was observed in the auditory thalamus during SWS [Edeline et al. (2000), J. Neurophysiol., 84, 934]. It also contrasts with the receptive field enlargement that was described under anaesthesia when the EEG spontaneously shifted from a desynchronized to a synchronized pattern [Wörgötter et al. (1998), Nature, 396, 165]. Reasons for these differences are discussed.
\end{abstract}

\section{Introduction}

That sensory systems process information from the outside world differently during wakefulness and sleep seems a trivial statement. However, examination of the literature rapidly reveals the paucity of experimental evidence supporting this view. Understanding the way sensory neurons process information requires, at least, quantification of the basic receptive field (RF) properties, such as the neurons' selectivity for a given stimulus dimension and the size of the suprathreshold receptive field. These properties are classicaly described under general anaesthesia, but so far very few studies have examined how they change across natural states of vigilance. In fact, the study performed by Livingstone \& Hubel (1981) in the visual cortex has long been the only one reporting modifications in RF properties when the level of arousal changed in unanaesthetized animals. On arousal from drowsiness or from brief episodes of slowwave sleep (SWS), cortical neurons showed either unaffected or enhanced responses to visual stimuli. As these responses usually occurred against a lowered and more regular background firing, the signal-to-noise ratio was increased. On awakening, the specificity of responses was usually unchanged, but it was slightly improved for some cells that exhibited an enhanced selectivity for orientation or movement direction.

Sleep-dependent changes in the central auditory system were explored in four single-unit studies (Pena et al., 1992, 1999; Pedemonte et al., 1994; Morales-Cobas et al., 1995), but they only

Correspondence: Dr Jean-Marc Edeline, as above.

E-mail: jean-marc.edeline@ibaic.u-psud.fr

Received 10 June 2001, revised 10 October 2001, accepted 23 October 2001 concerned responses evoked by a single acoustic stimulus. Recently, we described how the RF properties of auditory thalamus neurons were modified when an undrugged animal spontaneously shifted from one state of vigilance to another (Edeline et al., 2000). During SWS, thalamic cells behaved as a homogeneous population: for most of them, the spontaneous and evoked activities were both depressed compared with those in wakefulness; the result was an absence of change in the signal-to-noise ratio. As a consequence of the decreases in evoked responses, the RF size was reduced and the frequency selectivity was enhanced. These results clearly differed, thus, from those obtained in the visual cortex (Livingstone \& Hubel, 1981). To evaluate whether these discrepancies reflect differential effects of behavioural state changes in the auditory and visual systems or differential effects at the thalamic and cortical levels, we tested basic RF properties of auditory cortex neurons during SWS and wakefulness.

\section{Materials and methods}

\section{Animal preparation}

Adult male guinea pigs $(n=10)$ that weighed $400-600 \mathrm{~g}$ at the time of the initial surgery were used. They received an injection of atropine $(0.08 \mathrm{mg} / \mathrm{kg})$ and Diazepam $(8 \mathrm{mg} / \mathrm{kg})$, followed $15 \mathrm{~min}$ later by an injection of pentobarbital (20 mg/kg; see Evans, 1979). Three silver-ball electrodes were inserted between bone and dura: one was used as reference during the recording sessions; the other two, placed over the frontal and parietal cortex, served to monitor the cortical electroencephalogram (EEG). A bipolar electrode was 
lowered into the right hippocampus just above CA1 (3 mm under the pia) to record the hippocampal electroencephalogram. Two silver wires were inserted into the dorsal neck muscles to record electromyographic activity. A recording chamber was placed on the temporal bone over the auditory cortex ( $4.5 \mathrm{~mm}$ posterior to bregma) on each side of the brain. A pedestal of dental acrylic cement, including three cylindrical threaded tubes, was built to allow atraumatic fixation of the animal's head during the subsequent recording sessions. An antiseptic ointment (Cidermex, neomycine sulphate, Rhone-Poulenc Rorer) was liberally applied in the wound around the pedestal, and an antibiotic (Josacine, Josamycine propionate $8 \mathrm{mg} / \mathrm{kg}$, Rhone-Poulenc Rorer) was administered orally for the 5 days following surgery.

Three days after surgery, the animals were adapted for several days to restrained conditions in an acoustically isolated chamber (IAC, New York, USA; model AC2). They were placed in a hammock with the head fixed for increasing periods of time (2-6 h/day). They were also accustomed to hearing sequences of pure tones. At the end of this period of adaptation, the animals displayed alternations of waking, SWS and paradoxical sleep (PS).

After 7-10 days of adaptation, the animal was anaesthetized and the bone covering the auditory cortex within one of the two chambers was removed. A rough mapping of the auditory cortex was performed with low impedance electrodes to localize the primary tonotopic field. The chamber was then hermetically closed with a silicon elastomeric impression material (Basylex Monophase, Bayer). Starting the day following this trepanation, daily recording sessions $(2-4 \mathrm{~h})$ were performed on this hemisphere. After 3-6 days of recording, the bone covering the second chamber was removed under anaesthesia, and $3-$ 6 daily recording sessions were performed in the other hemisphere. We stress the fact that none of the animals was drugged or sleepdeprived before the recording sessions.

Aseptic procedures were used during the initial surgery and the subsequent craniotomies. All procedures were performed in conformity with national (JO 887-848) and European (86/609/EEC) legislations on animal experimentation. In addition, regular inspections of our laboratory by accredited veterinarians designed by ParisSud University attested that appropriate cares were taken to maximize the animals' health and comfort throughout the different phases of the experiment.

\section{Recording procedures}

Tungsten electrodes $(0.5-2.5 \mathrm{M} \Omega$ at $1000 \mathrm{~Hz})$ were inserted through a small puncture made in the dura under microscopic control, and were lowered in the auditory cortex using a hydraulic micromanipulator (Narashige; $2-\mu \mathrm{m}$ step). The signal coming from the electrode was amplified (bandpass $0.6-10 \mathrm{kHz}$, gain 5000) and sent in parallel to an audio monitor and to a voltage window discriminator (Frederic Haer Inc., model 74-60-1). No waveform sorting system was used; thus, only one single-unit waveform was isolated from the signal coming from the electrode. The waveform of the unit and the corresponding pulses generated by the discriminator were constantly displayed on the screen of a digital oscilloscope. During each recording session, meticulous care was taken to ensure that the same unit was recorded throughout the session, and data collection was immediately stopped when the waveform was unstable. The TTL pulses generated by the window discriminator were sent to the acquisition board (PClab, PCL 720) of a Pentium II CPU computer. Using a subroutine written in assembly language, the time of occurrence of the TTL pulses corresponding to each action potential was known with a resolution of $50 \mu$ s. The single-unit waveforms were digitized (50-kHz sampling rate; GW Instruments, Superscop software) during all the recording sessions to check for their stability.

\section{Stimulus generation}

The sound generating system was the same as in previous studies (Manunta \& Edeline, 1997, 1999; Edeline et al., 1999, 2000). Pure tone frequencies were generated by a remotely controlled wave analyser (Hewlett-Packard, model HP 8903B) and attenuated by a passive programmable attenuator (Wavetek, P557; maximal attenuation $127 \mathrm{~dB}$ ); both were controlled by a computer via an IEEE bus. Contralateral tones were delivered through an earphone mounted in a small stainless steel container filled with foam. The opening of the container was fitted into the ear canal to deliver the stimuli close to the tympanic membrane. The determination of the power output of the sound delivery system was made with respect to a reference tone $(1 \mathrm{kHz}$ at $94 \mathrm{~dB}$ re $20 \mu \mathrm{Pa})$ generated by a sound level calibrator (Bruel \& Kjaer, model 4230). A condenser microphone/preamplifier (B \& K models 4133 and 2639T) was placed inside the opening of the calibrator. The output was sent to the wave analyser, and the value obtained, together with the microphone calibration curve supplied by B \& K (free-field curve), allowed the conversion of additional values into absolute sound pressure level (SPL) values. The microphone/ preamplifier was then placed in front of the opening of the sound transmission tube at approximately the same location as the tympanic membrane with respect to the end of the sound tube during the experiments. For each frequency passing through the earphone and the microphone/preamplifier, the power output for that frequency was determined by the wave analyser. The values were converted into SPL values. A calibration curve was produced by converting the deviations from the intensity of the reference tone into absolute values for each frequency. Six ascending sequences of 11 isointensity tones were used: $0.1-1.1 \mathrm{kHz}$ (stepping frequency $100 \mathrm{~Hz}$ ); $0.3-$ $2.3 \mathrm{kHz}$ (step $200 \mathrm{~Hz}$ ); $1-11 \mathrm{kHz}$ (step $1 \mathrm{kHz}$ ); $5-15 \mathrm{kHz}$ (step $1 \mathrm{kHz}$ ); $10-20 \mathrm{kHz}$ (step $1 \mathrm{kHz}$ ); $15-35 \mathrm{kHz}$ (step $2 \mathrm{kHz}$ ). The sound delivery system can deliver tones of $90 \mathrm{~dB}$ up to $20 \mathrm{kHz}$ and of $70 \mathrm{~dB}$ up to $35 \mathrm{kHz}$. Harmonic distortion products were $60 \mathrm{~dB}$ down from the fundamental. Although the intensities used were calibrated with respect to the SPL scale, the intensities expressed here are best viewed as relative values, given that a sealed sound system cannot be used in awake animals.

\section{Experimental protocol}

At each recording session, once a clear single-unit waveform was observed, repeated ascending sequences of 11 pure tone frequencies (100-ms tone duration, 5-ms rise-fall time, 1-s intertone interval) were delivered, until the sequence of tones the most appropriate to cover the neuron's receptive field was found. The selected sequence was initially presented at different intensities (using 10-dB steps). Then, an intensity of $40 \mathrm{~dB}$ above the neuron's threshold was chosen and the sequence was continuously presented at this intensity. Ten successive repetitions of this sequence were used to quantify the frequency response function (FRF). Thus, each test of the FRF lasted $110 \mathrm{~s}$. The data corresponding to every test of the FRF were stored on the computer hard drive.

The electroencephalograms (bandpass 1-90 Hz) and the electromyogram (bandpass 3-90 Hz) were digitized (1-kHz sampling rate; Mac Adios II board, GW Instrument) and were monitored on a polygraph (Grass model 79D) during all the recordings sessions to determine the state of vigilance.

The recording session was stopped each time a waveform different from that stored at the beginning of the session passed the threshold 
of the voltage window discriminator. Successive neuronal recordings were separated by at least $100 \mu \mathrm{m}$.

\section{Data analysis}

After each recording session, the polygraphic recordings were examined independently by two investigators. Only the FRFs unambiguously recorded during continuous and stable periods of waking, SWS or PS were analysed. As the vigilance state of the animals fluctuated in an unpredictable manner, the probability that the $110 \mathrm{~s}$ corresponding to the determination of the FRF belonged entirely to a stable vigilance state was very low. The consequence was that only $10 \%$ of the FRFs obtained during a recording session were analysed; the remaining $90 \%$, obtained from mixed vigilance states, were not further considered.

Spontaneous activity was quantified during the $500 \mathrm{~ms}$ preceding each tone. Such quantification was found to provide values similar to those obtained when spontaneous activity was collected during longer periods ( $2 \mathrm{~min}$ ) without tone presentation (Manunta \& Edeline, 1997, 1999). In agreement with the literature that has categorized the excitatory evoked responses in unanaesthetized animals (Abeles \& Goldstein, 1972; Brugge \& Merzenich, 1973; Recanzone et al., 2000; Recanzone, 2000), we observed either 'on' (phasic) responses or 'sustained' (tonic) responses. On the basis of the observed pattern of response, a time window $(0-25,0-50$ or $0-100 \mathrm{~ms})$ was selected to analyse the responses of a given neuron. Only excitatory responses were considered; inhibitory responses were not. We did not analyse either 'off' responses or 'labile' responses which progressively habituated during repetition of the tone sequence even when the vigilance state was constant. Cells that could not be driven by any pure tone stimuli but that, in many cases, responded to click or complex stimuli were also discarded.

For each cell, the FRFs were plotted and the following variables were analysed. The mean evoked response (Mean) was defined as the response averaged across the 11 frequencies used to determine the FRF. The best frequency (BF) was defined as the frequency eliciting the strongest evoked responses. The signal-to-noise ratio was computed by dividing the tone-evoked response by the spontaneous activity, using as signal (i) the mean evoked response (Mean/Spon) and (ii) the response at the $\mathrm{BF}(\mathrm{BF} / \mathrm{Spon})$.

As in previous experiments (Manunta \& Edeline, 1997, 1999; Edeline et al., 1999, 2000), the frequency selectivity was quantified using the following index:

[(Response at the $\mathrm{BF}-$ Mean evoked response)/(Response at the $\mathrm{BF}) \textrm{ } \times 100$

This index is similar to that used in the visual system to quantify the orientation selectivity (Bienenstock et al., 1982; Frégnac et al., 1992). An index approaching 100 means that excitatory responses occurred only at the $\mathrm{BF}$, whereas an index equal to 0 means that the cell gave similar responses at all the frequencies used to generate the FRF.

The latency of the tone-evoked responses was computed by determining the latency of the first spike after tone onset (1-ms precision) from the responses obtained for all the frequencies tested. For each cell, the variability of the latency was quantified by the standard deviation of the mean latency value.

The RF size was quantified using two different indices. The first was the $\mathrm{Q}_{40 \mathrm{~dB}}$ (Kiang et al., 1965; Schreiner \& Mendelson, 1990). With this index, the higher the value the sharper the RF size. The second was the square root transformation $\sqrt{f}_{2}-\sqrt{f}_{\mathrm{f}}$, where $\mathrm{f} 2$ and $\mathrm{f} 1$ indicate the high and low limits of the FRF breadth at $40 \mathrm{~dB}$ above threshold; with this measurement, the breadth of tuning is independent of the characteristic frequency (Whitfield, 1968; Whitfield \&
Purser, 1972; Calford et al., 1983). With this index, the lower the value the sharper the RF size.

To assess whether changes in discharge mode occurred across states, a 'burstiness index' (BI) was calculated for each cell in each vigilance state. As in previous studies (Guido et al., 1992; Lu et al., 1992; Mukherjee \& Kaplan, 1995; Edeline et al., 2000), we used an empirical gauge of the neurons burstiness by computing the percentage of intervals $\leqslant 4 \mathrm{~ms}$ in the interspike interval distribution. The BI was computed separately for periods of spontaneous activity (between tone presentations) and for periods of evoked activity (during tone presentations).

Two types of statistical comparisons were carried out. First, for each of the parameters measured, between-state comparisons were made using Student's paired $t$-tests. Second, individual comparisons were made for each cell, to determine whether the activity of the cell was significantly affected by behavioural state changes. The values of spontaneous and of evoked activity obtained for a cell during SWS or during PS were compared with those obtained for that cell during waking, using paired $t$-tests. The level of $P<0.05$ was used to assign each cell to a given category: decreased, increased or unchanged activity.

\section{Histology}

At the end of the last recording session, a small electrolytic lesion was made by passing anodal current $(10 \mu \mathrm{A}, 10 \mathrm{~s})$ through the electrode. The animal received a lethal dose of nembutal $(200 \mathrm{mg} / \mathrm{kg})$ and was perfused intracardially with $0.9 \%$ saline $(200 \mathrm{~mL})$ followed by $2000 \mathrm{~mL}$ of fixative (4\% paraformaldehyde in $0.1 \mathrm{M}$ phosphate buffer, $\mathrm{pH}$ 7.4). The brains were put in a $30 \%$ sucrose solution for $3-$ 4 days. Coronal serial sections of the brain were cut on a freezing microtome $(50-\mu \mathrm{m}$ thickness) and stained with cresyl violet. The sections were examined under several microscopic magnifications to determine the location of the last cell recorded. The locations of the other recorded cells were estimated based on (i) the depth after dura penetration, and (ii) the $x$ and $y$ coordinates of penetrations within the recording chamber.

\section{Results}

\section{General characteristics of the recorded neurons}

A database of 246 cells exhibiting consistent evoked responses to pure tone frequencies and a reliable frequency tuning was initially collected. Of these cells, 56 were successfully tested during unambiguous periods of both waking and SWS; 12 were tested in waking and PS (six of them were also tested in SWS). These small numbers were not the consequence of unstable recordings, but of the low probability of obtaining, for the same cell, a frequency response function entirely in waking, then entirely in SWS and/or in PS.

Neurons were recorded in the anterior tonotopic field (AI; Redies et al., 1989; Wallace et al., 2000) from 250 to $1800 \mu \mathrm{m}$ after dura penetration. The time period during which a cell was recorded ranged from $30 \mathrm{~min}$ to $2 \mathrm{~h} 30 \mathrm{~min}$ (mean $45 \mathrm{~min}$ ). The spike amplitudes were from 300 to $1200 \mu \mathrm{V}$, with a noise level usually $<100 \mu \mathrm{V}$.

The presentation of the results is focused on the comparisons between waking and SWS, which rely on a substantial number of cells $(n=56)$. The comparisons between waking and PS, which rely on a smaller cells sample $(n=12)$, are presented more briefly in the last paragraph. 

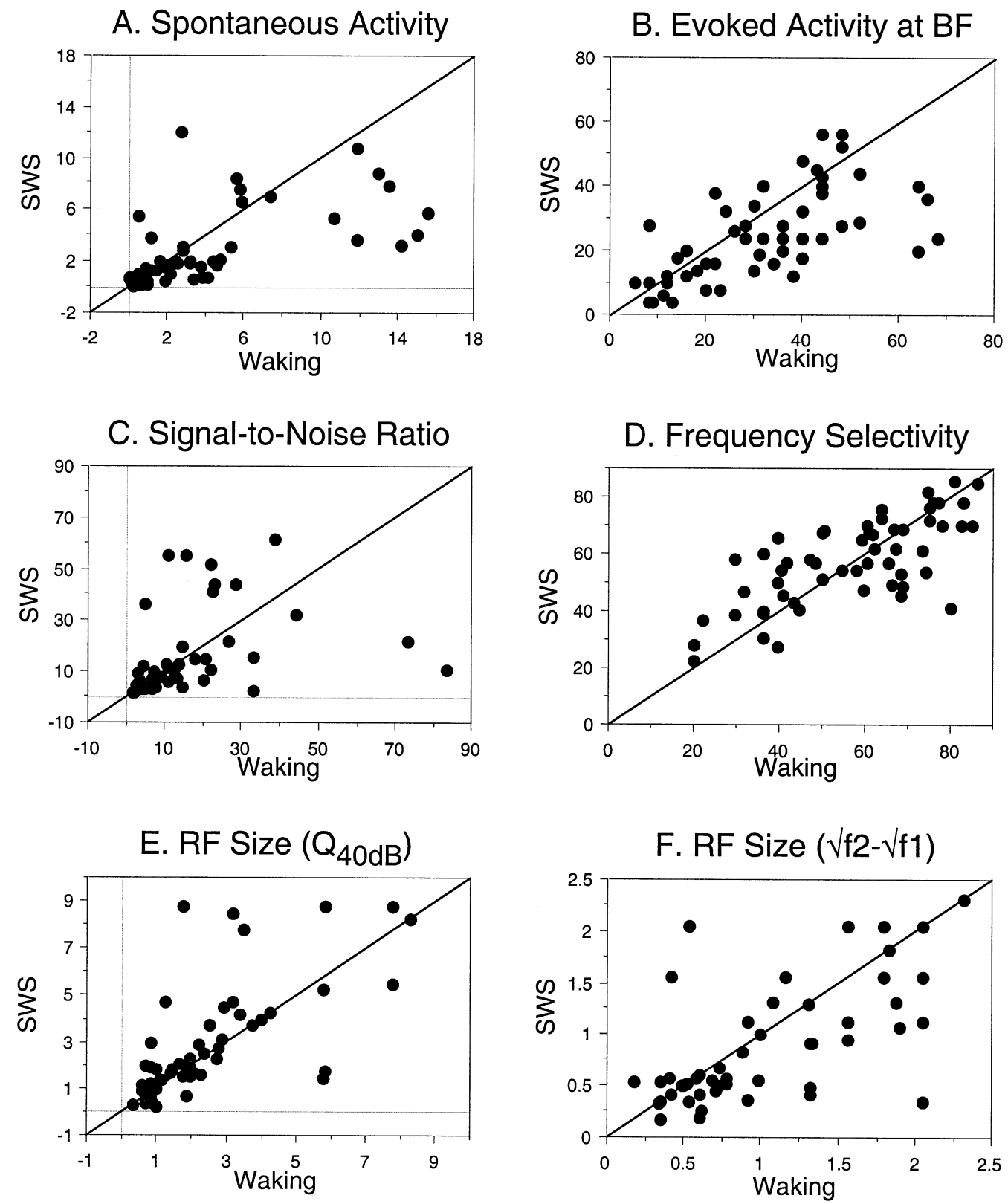

FIG. 1. Scattergrams of data obtained for the 56 cells tested during waking and slow-wave sleep (SWS). (A and B) For most of the cells, the spontaneous activity and the responses evoked at the best frequency (BF) were decreased in SWS compared with waking. (C and D) There was no dominant statedependent effect for the signal-to-noise ratio (response at the BF/spontaneous activity) or for the frequency selectivity index (which quantified the relative weight of the response at the BF compared with the responses at the other frequencies). (E and F) The receptive field (RF) size was quantified by the $\mathrm{Q}_{40 \mathrm{~dB}}$ (with this index, the higher the value the sharper the RF size) and by the square root transform (with this index, the lower the value the sharper the RF size). Though a substantial number of cells showed a decreased RF size in SWS, no significant difference existed between SWS and waking over the whole population, whatever the index used.

Changes in spontaneous and evoked activities during SWS; consequences on the signal-to-noise ratio

The scattergrams in Fig. 1A and B show the changes in spontaneous and evoked activities for the 56 cells recorded in SWS and waking. During SWS, spontaneous activity was lower than during waking, but the difference did not reach significance $\left(t_{55}=1.26, P=0.07\right.$; see values in Table 1). The mean evoked response and the response at the best frequency (BF) were significantly decreased (Mean: $t_{55}=2.64$, $P=0.01 ;$ BF: $\left.t_{55}=3.35, P=0.001\right)$. As both spontaneous and evoked activities usually changed in the same direction (being often decreased in SWS), the signal-to-noise ratio was not significantly modified $\left(t_{55}<1\right.$, using as signal either the Mean or the BF; see Fig. 1C). The proportions of cells exhibiting significant changes $(P<0.05)$ of their spontaneous and/or evoked firing rate confirmed these averaged group data. As shown in Table 2, spontaneous activity was unchanged for 29 cells, decreased for 20 cells and increased for only seven cells. The evoked responses were decreased for 27 cells, unchanged for 21 cells and increased for only eight cells. The individual examples shown in Figs 2-5 illustrate these different patterns of changes: whereas the mean evoked response was strongly 
TABLE 1. Changes in physiological parameters observed for the 56 cells tested during slow-wave sleep and waking

\begin{tabular}{|c|c|c|}
\hline Parameter & Waking & Slow-wave sleep \\
\hline $\begin{array}{l}\text { Spontaneous activity } \\
\text { (spikes/s) }\end{array}$ & $4.73 \pm 0.75$ & $3.93 \pm 0.78$ \\
\hline \multicolumn{3}{|l|}{ Evoked activity } \\
\hline Mean (spikes/s) & $15.33 \pm 1.39$ & $12.00 \pm 1.46^{*}$ \\
\hline BF (spikes/s) & $34.75 \pm 2.75$ & $27.05 \pm 2.75^{*}$ \\
\hline \multicolumn{3}{|l|}{ Signal-to-noise ratio } \\
\hline Mean/Spon & $9.58 \pm 2.52$ & $7.14 \pm 1.12$ \\
\hline BF/Spon & $27.99 \pm 8.08$ & $21.56 \pm 4.49$ \\
\hline Selectivity index & $56.75 \pm 2.41$ & $57.77 \pm 2.02$ \\
\hline \multicolumn{3}{|l|}{ RF size } \\
\hline$\sqrt{f}_{\mathrm{f} 2}-\sqrt{\mathrm{f}} \mathrm{f}$ & $1.08 \pm 0.85$ & $0.98 \pm 0.10$ \\
\hline $\mathrm{Q}_{40 \mathrm{~dB}}$ & $2.83 \pm 0.39$ & $3.20 \pm 0.41$ \\
\hline $\begin{array}{l}\text { Response latency } \\
\text { (ms) }\end{array}$ & $26.62 \pm 1.56$ & $27.16 \pm 1.42$ \\
\hline $\begin{array}{l}\text { Latency variability } \\
\quad(\mathrm{ms})\end{array}$ & $14.71 \pm 0.98$ & $15.56 \pm 0.98$ \\
\hline \multicolumn{3}{|l|}{ Burstiness index } \\
\hline BI spontaneous & $8.69 \pm 1.08$ & $9.34 \pm 1.31$ \\
\hline BI evoked & $24.61 \pm 3.48$ & $30.98 \pm 4.04 *$ \\
\hline
\end{tabular}

For each state and each parameter, the mean value is shown \pm SEM. Mean, mean evoked response; $\mathrm{BF}$, response at the best frequency; spon, spontaneous activity; BI, burstiness index. $* P<0.05$ compared with waking (paired $t$-tests).

depressed during SWS for the two cells presented in Figs 2 and 3, it was not significantly changed for the cell presented in Fig. 4, and it was increased for the cell presented in Fig. 5.

\section{Changes in frequency selectivity and receptive field size during SWS}

The frequency selectivity was determined for each cell using an index that quantified the relative weight of the response at the BF compared with the responses evoked at the other frequencies (see Materials and methods). When the values of the selectivity index were averaged over the 56 cells, no significant difference emerged between SWS and waking $\left(t_{55}<1\right.$; see Table 1 and Fig. 1D). However, more detailed analyses revealed that the frequency selectivity in SWS was differentially affected depending on the changes in the mean evoked responses. The selectivity index was higher in SWS than in waking for the subset of 27 cells that exhibited depressed evoked responses ( $\left.t_{26}=2.82, P=0.009\right)$; it was lower for the eight cells that exhibited increased evoked responses $\left(t_{7}=2.76, P=0.028\right)$; it was unchanged for the 21 cells that exhibited unchanged responses $\left(t_{20}<1\right)$.

The receptive field size was quantified both by the square root transform and by the $\mathrm{Q}_{40 \mathrm{~dB}}$ (see Materials and methods). The results obtained with these two quantifications are shown in the scattergrams $\mathrm{E}$ and $\mathrm{F}$ of Fig. 1. On average, the values obtained during SWS did not differ from those obtained during waking, whether using the square root transform ( 1.08 vs. $\left.0.98 ; t_{55}=1.33, P=0.18\right)$ or the $\mathrm{Q}_{40 \mathrm{~dB}}\left(2.83\right.$ vs. $\left.3.20 ; t_{55}=1.03, P=0.30\right)$. However, as was the case for the selectivity index, the RF size in SWS varied as a function of the changes in evoked responses (see Fig. 6A). It was unchanged for the cells whose evoked responses were not modified (with the square root transform: $t_{20}<1$ ), reduced for the cells whose responses were decreased $\left(t_{26}=4.10, P=0.0004\right)$, and enlarged for the cells whose responses were increased $\left(t_{7}=2.52, P=0.039\right)$. The examples shown in Figs 2-5 illustrate these two opposite effects: for the two cells presented in Figs 2 and 3, there was a reduction of the RF during SWS; in contrast, for the two cells presented in Figs 4 and 5, there was an expansion of the RF during SWS.
TABLE 2. Proportions of cells showing significant changes in spontaneous and/or evoked activity during slow-wave sleep

\begin{tabular}{|c|c|c|c|c|c|c|c|c|}
\hline & \multicolumn{8}{|c|}{ Evoked activity } \\
\hline & \multicolumn{2}{|c|}{ Decrease } & \multicolumn{2}{|c|}{ Increase } & \multicolumn{2}{|c|}{ No change } & \multicolumn{2}{|c|}{ Total } \\
\hline & $n$ & $(\%)$ & $n$ & $(\%)$ & $n$ & $(\%)$ & $n$ & $(\%)$ \\
\hline \multicolumn{9}{|c|}{ Spontaneous activity } \\
\hline Decrease & 14 & $25 \%$ & 1 & $2 \%$ & 5 & $9 \%$ & 20 & $36 \%$ \\
\hline Increase & 1 & $2 \%$ & 5 & $9 \%$ & 1 & $2 \%$ & 7 & $12 \%$ \\
\hline No change & 12 & $21 \%$ & 2 & $4 \%$ & 15 & $27 \%$ & 29 & $52 \%$ \\
\hline Total & 27 & $48 \%$ & 8 & $14 \%$ & 21 & $38 \%$ & 56 & $100 \%$ \\
\hline
\end{tabular}

For each cell, the spontaneous activity and the mean evoked response obtained during slow-wave sleep were compared with the values obtained during waking, using paired $t$-tests, and the level of $P<0.05$ was used to assign the cell to a given category. $n$, number of cells.

\section{Changes in responses latency during SWS}

In each vigilance state, the latency of the evoked responses was quantified by the latency of the first spike after tone onset (see Materials and methods). On average, neither the response latencies nor the latency variability differed between SWS and waking $\left(t_{55}<1\right.$ in both cases). However, as shown in Fig. 6B, a more detailed analysis revealed that the latency was lengthened in SWS for the cells whose evoked responses were decreased $\left(t_{26}=2.08, P=0.046\right)$; it tended to be shortened for the cells whose responses were increased $\left(t_{7}=2.02, \quad P=0.083\right)$; it was unchanged for the cells whose responses were unchanged $\left(t_{20}<1\right)$.

\section{Changes in discharge mode during SWS; relationships with other parameters}

As in previous studies (see Materials and methods), a 'burstiness index' (BI) was calculated for each cell in each vigilance state, during both spontaneous and evoked activity, to determine if changes in discharge mode occurred across states.

Within each state of vigilance, the mean value of the BI was higher during tone presentations than during spontaneous activity $(P<0.0001$ in all cases). As shown in Fig. 7 , the BI value was higher during SWS than it was in waking during tone periods $\left(t_{55}=2.01, P=0.049\right)$; it was not significantly changed during spontaneous activity $\left(t_{55}<1\right)$. These results indicate that at tone presentation there was a higher probability that the cells responded by a burst of action potentials during SWS than during waking, whereas between tone presentations the cells did not exhibit more bursts in SWS than in waking.

None of the systematic analyses that were performed to determine whether the changes in firing mode influenced the other parameters quantified across states revealed any significant effects. For example, it appeared that the changes in discharge mode occurred independently of the changes in discharge rate; during SWS, the BI was increased whatever the change in evoked activity. Moreover, when we considered a population of 14 cells that exhibited each a $>20 \%$ BI increase above waking values during tone periods, this population did not show significant changes in evoked activity, responses latency or latency variability $\left(t_{13}<1\right.$ in all cases).

Both during the recording sessions and during the subsequent offline analyses, it was very difficult to assign the cells to classical categories such as regular-spiking, fast-spiking, and intrinsically bursting neurons, as defined by in vitro studies (McCormick et al., 1985; Connors \& Gutnick, 1990). In fact, during waking, most of the cells exhibited firing patterns that were composed mostly of single 

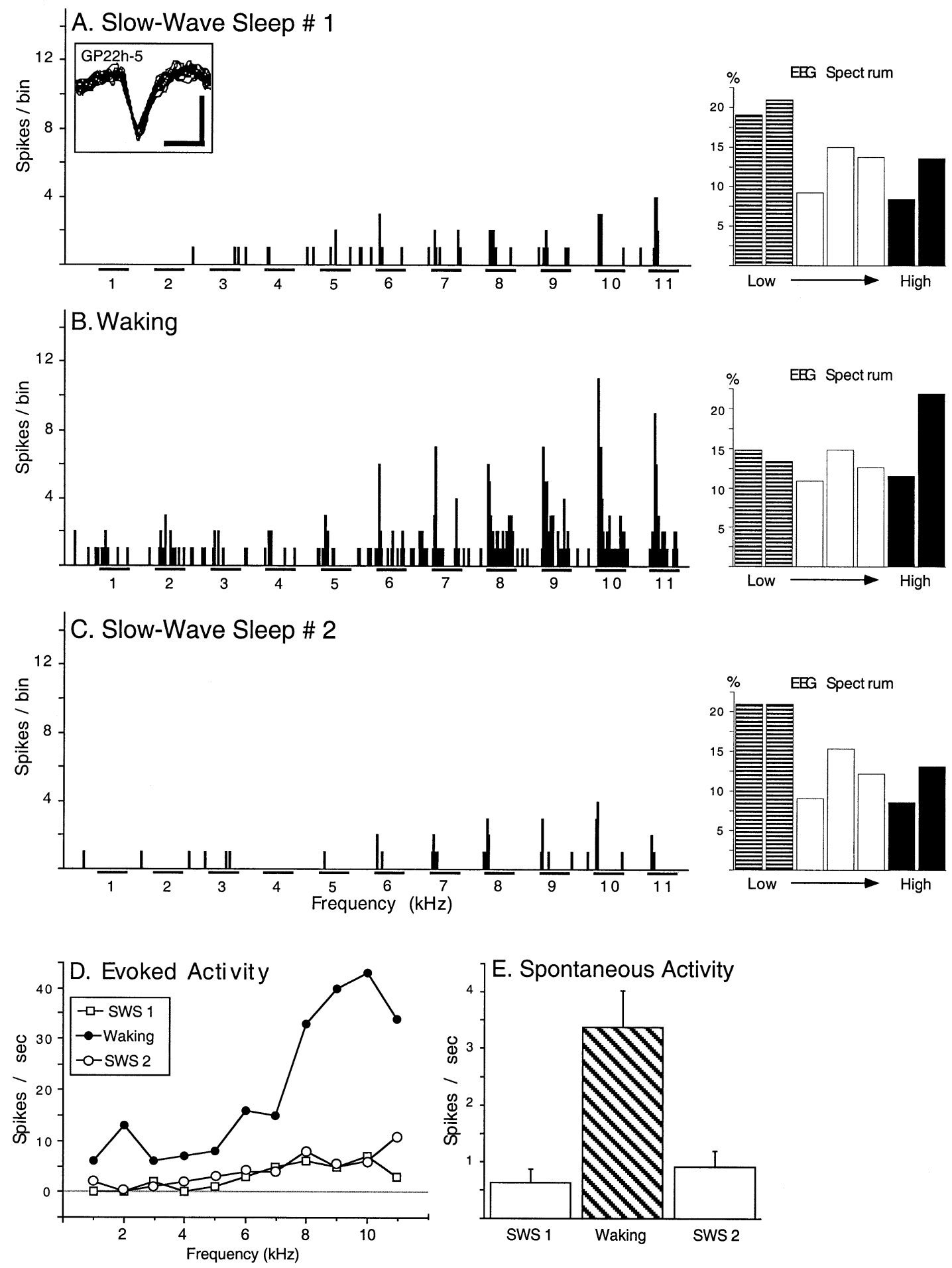

FIG. 2. Decreases in evoked and spontaneous activities during SWS. The cell (GP22h-5; scale bars, $300 \mu \mathrm{V}, 0.5 \mathrm{~ms}$ ) was recorded $1310 \mu \mathrm{m}$ below pia and was tested at $60 \mathrm{~dB}$ during SWS, then during waking, then again during SWS; it was not tested during PS. (A and C) During SWS small phasic responses were observed from 6 to $11 \mathrm{kHz}$. (B) During waking, strong evoked responses were observed between 2 and $11 \mathrm{kHz}$; these responses exhibited a sustained component that was not present during SWS. (D) The quantification of the evoked reponses shows the stability of the responses in SWS and their strong attenuation compared with those in waking. (E) Spontaneous activity was significantly lower during SWS than during waking. In this figure, as in all the following individual figures, the histograms (5-ms bin) display the cell's activity during 10 repetitions of a sequence of 11 ascending frequencies at $40 \mathrm{~dB}$ above threshold. The short bars below the horizontal axis denote the $100 \mathrm{~ms}$ of tone duration, and only the $100 \mathrm{~ms}$ immediately preceding each tone are presented. The numbers below the short bars are the values of the tone frequencies in $\mathrm{kHz}$. The insert at the top of the figure displays the waveform of the action potential ( 30 sweeps, $50-\mathrm{kHz}$ sampling rate). From the EEG signals, fast Fourier transforms (FFT) were computed and the areas of seven representative frequency bands were derived from the FFT. These seven frequency bands, plotted on the right of each histogram, represent 1-3, 3-6, 6-8, 8-12, 12-17, 1722 and $22-50 \mathrm{~Hz}$. As it can be seen on all the examples presented, the percentages of the two lowest frequency bands were larger during SWS than during waking, whereas the percentages of the two highest frequency bands were smaller. 
(isolated) spikes but also of bursts of action potentials. Only 10 of the 56 cells could be classified during waking, nine as regular-spiking and one as fast-spiking (action potential, $\leqslant 0.4 \mathrm{~ms}$ ). For the nine regular-spiking cells, the BI was unchanged from waking to SWS during spontaneous activity $\left(t_{8}<1\right)$; it was slightly higher in SWS than in waking during tone presentations $\left(t_{8}=1.64, P=0.14\right)$. The $\mathrm{BI}$ of the fast-spiking cell remained at zero during all three states of vigilance.
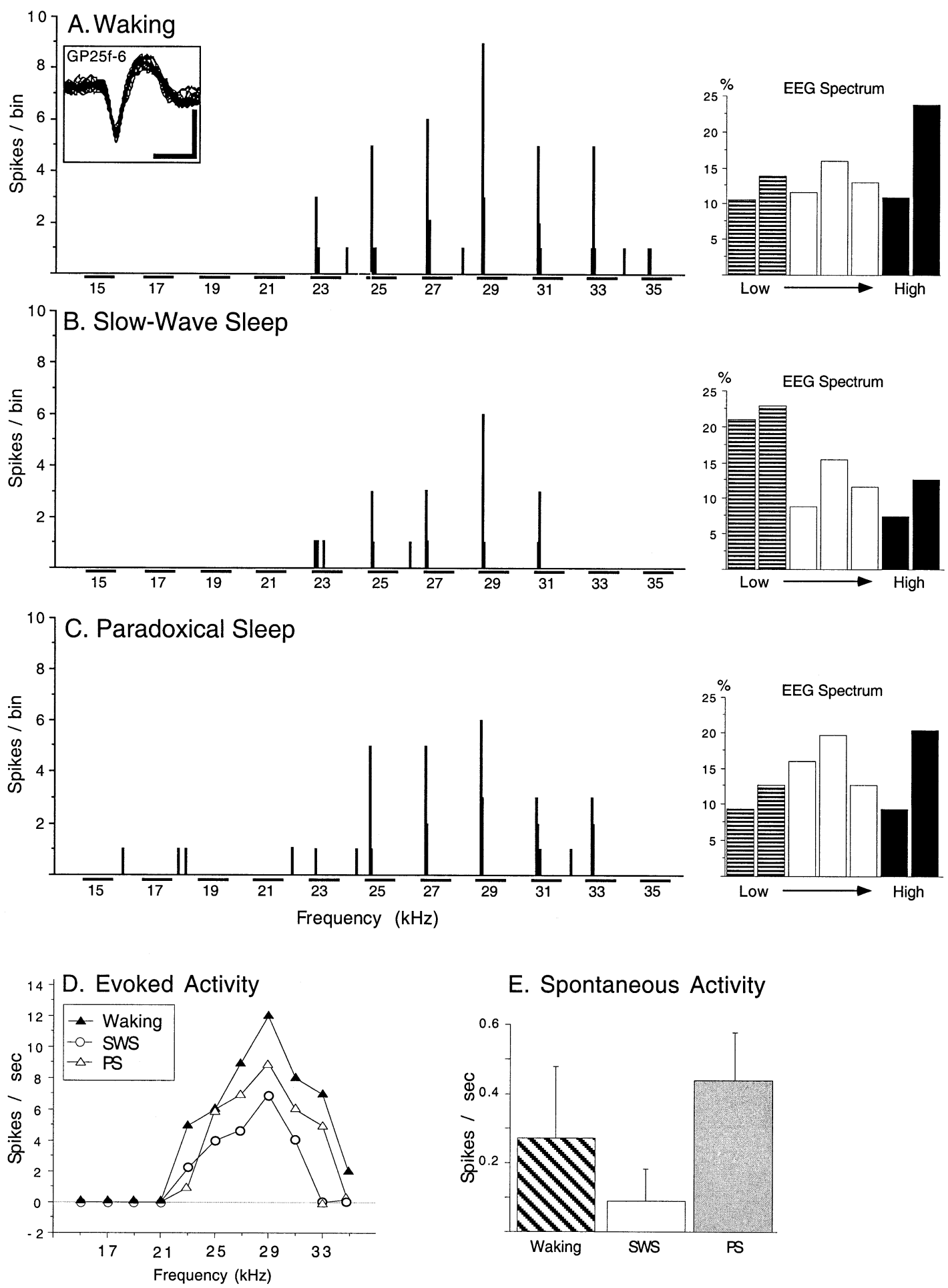

\section{E. Spontaneous Activity}

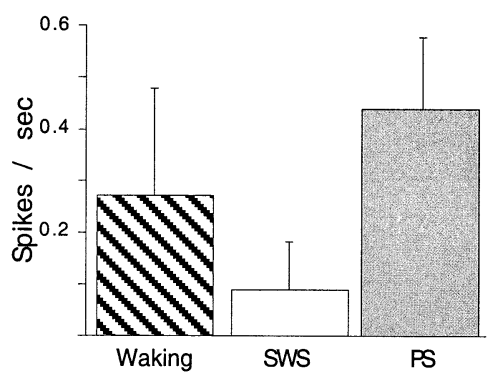

FIG. 3. Decreases in evoked activity during SWS and paradoxical sleep (PS).The histograms display the responses evoked at $50 \mathrm{~dB}$ in the RF of a cell (GP25f-6; scale bars, $300 \mu \mathrm{V}, 0.5 \mathrm{~ms}$ ) recorded $590 \mu \mathrm{m}$ below pia. The cell was tested successively during waking, SWS and PS. (A) During waking, evoked responses were observed from 23 to $33 \mathrm{kHz}$. (B) During SWS, responses of reduced magnitude were observed from 25 to $31 \mathrm{kHz}$. (C) During PS, evoked responses were observed from 25 to $33 \mathrm{kHz}$. (D) The quantification of the evoked reponses shows that the responses at all the frequencies were depressed during both SWS and PS. (E) Spontaneous activity was significantly decreased in SWS and not significantly increased in PS. Conventions as in Fig. 2. 

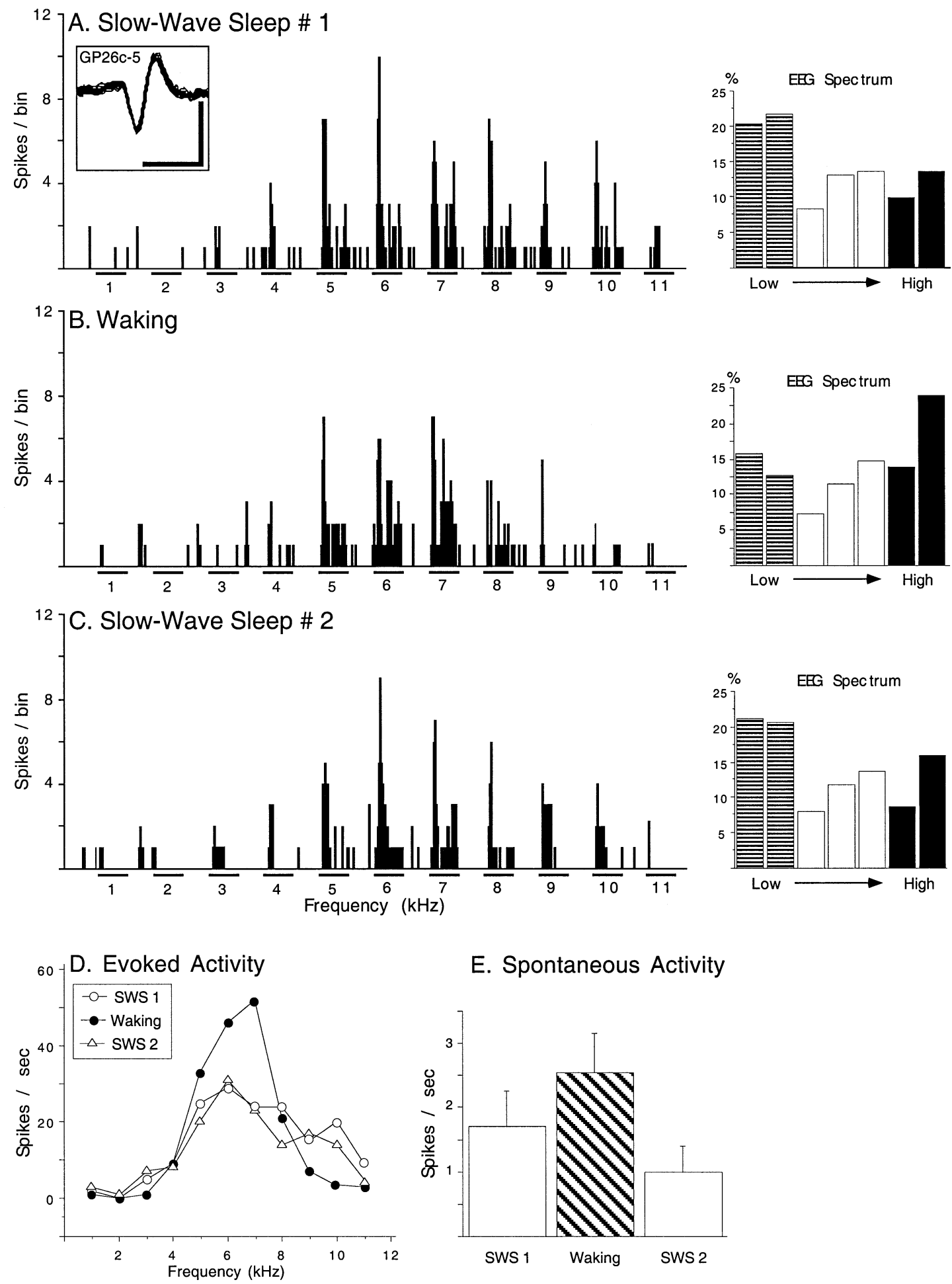

E. Spontaneous Activity

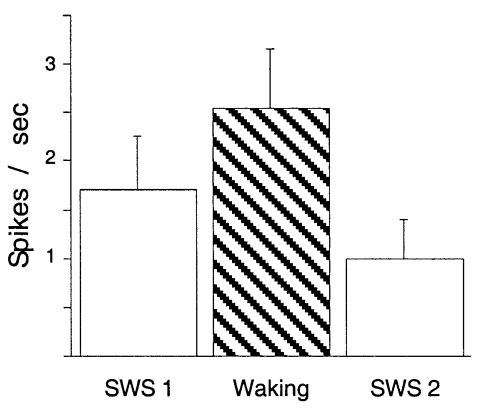

FIG. 4. Receptive field (RF) enlargement during SWS for a cell whose mean evoked response was unchanged. The histograms display the responses evoked at $70 \mathrm{~dB}$ in the RF of a cell (GP26c-5; scale bars, $400 \mu \mathrm{V}, 0.5 \mathrm{~ms}$ ) recorded $450 \mu \mathrm{m}$ below pia. The cell was tested during SWS, then during waking, then again during SWS; it was not tested during PS. (A) During SWS, evoked responses were observed from 3 to $11 \mathrm{kHz}$. (B) During waking, larger responses were observed from 5 to $7 \mathrm{kHz}$, but the responses at the borders of the RF disappeared (at 3, 10 and $11 \mathrm{kHz}$ ). (C) During a subsequent episode of SWS, the responses were similar to those obtained during the first SWS episode. (D) The quantification of the evoked reponses shows the enhancement (due to a sustained component) of the responses in the centre of the RF during waking and the appearance of responses at the RF borders during SWS. (E) Spontaneous activity was not significantly changed in SWS. Conventions as in Fig. 2. 
Potential relationships between the changes observed in SWS and cortical depth

The distribution of the 56 cells as a function of the cortical depth is presented in Fig. 8. Systematic analyses were performed to evaluate whether the sleep-related changes varied with the cortical depth. Firstly, the distributions of cells showing decreased, increased or unchanged spontaneous or evoked activity in SWS were compared. None of the $\chi^{2}$ tests performed revealed any significant differences in the distributions (lowest $P$-value, 0.19). Secondly, for each cell, the percentages of changes occurring from waking to SWS for the frequency selectivity, the RF size, the responses latency and the BI values (during spontaneous or evoked activity) were computed, and the correlation coefficients between these changes and the cortical depth were calculated. Whatever the physiological parameter considered, no significant relationship was found (lowest $P$-value, 0.51 ).
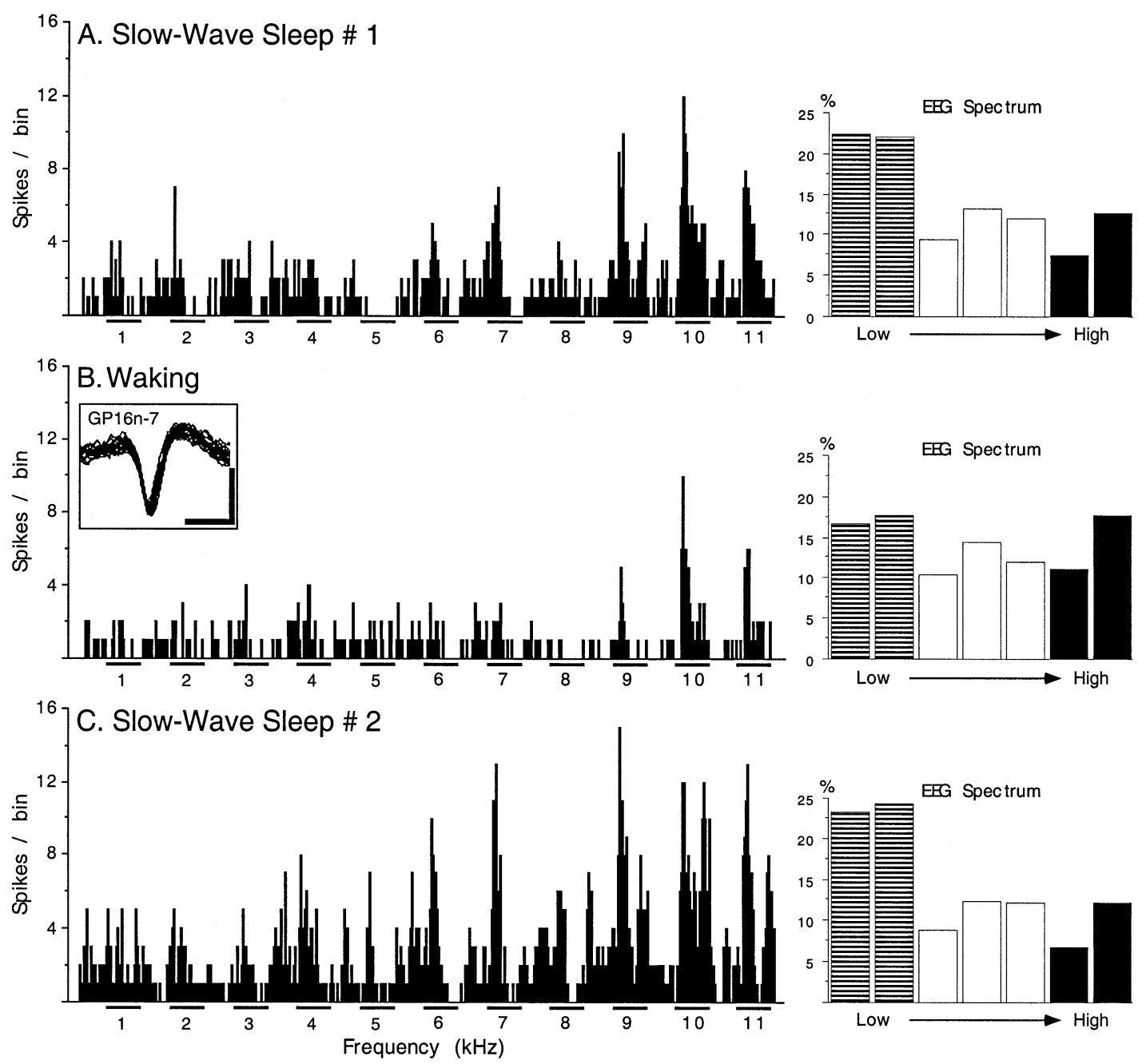

\section{Evoked Activity}

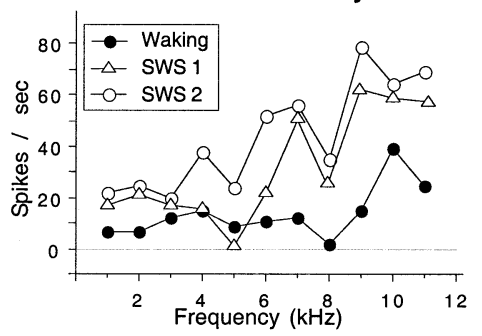

\section{E. Spontaneous Activity}

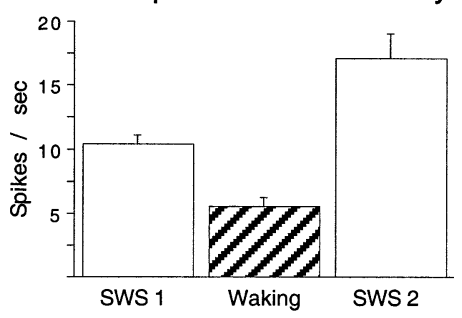

FIG. 5. Increases in evoked and spontaneous activities during SWS.The histograms display the responses evoked at $70 \mathrm{~dB}$ in the RF of a cell (GP16n-7; scale bars, $300 \mu \mathrm{V}, 0.5 \mathrm{~ms}$ ) recorded $1040 \mu \mathrm{m}$ below pia. The cell was tested successively during SWS, waking, and SWS again; it was not tested during PS. (B) During waking, clear evoked responses were only observed at 9, 10 and $11 \mathrm{kHz}$. (A and C) During the two episodes of SWS, the responses at these frequencies were largely increased (due to a prominent sustained component), and responses also occurred at other frequencies (6 and $7 \mathrm{kHz}$ ). (D) The quantification of the evoked responses shows the enhancement of the evoked responses and the enlargement of the RF in SWS. (E) Spontaneous activity was also significantly increased during SWS. 


\section{A. RF Size}

Decreased or Increased Evoked Responses

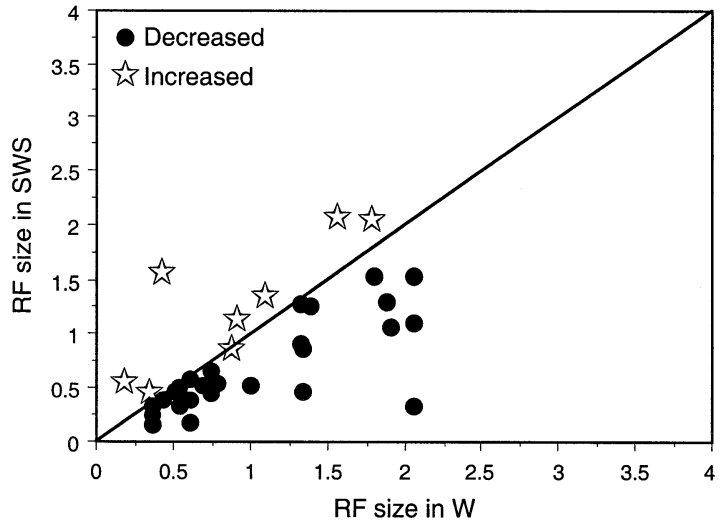

Unchanged Evoked Responses

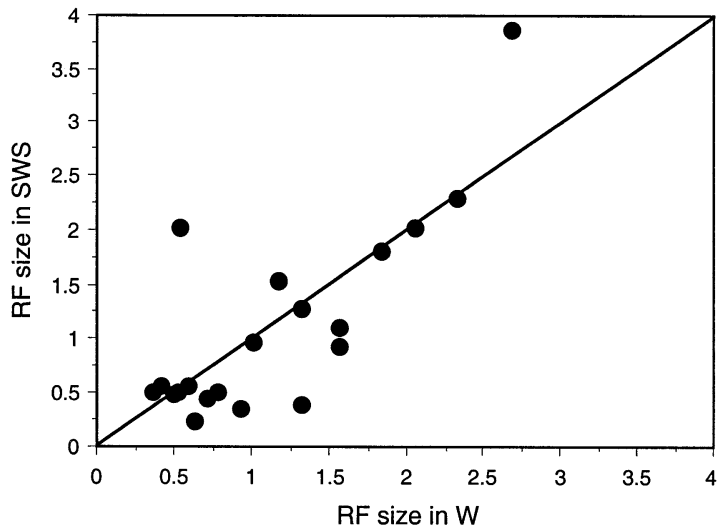

B. Responses Latency

\section{Decreased or Increased Evoked Responses}

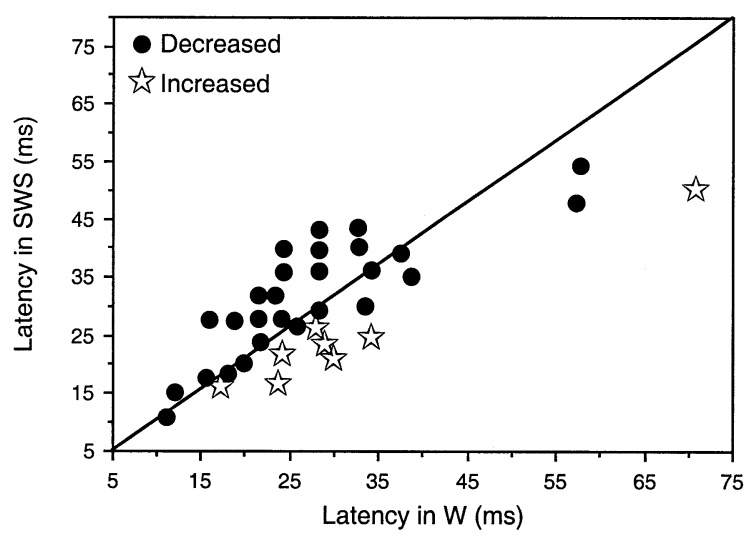

Unchanged Evoked Responses

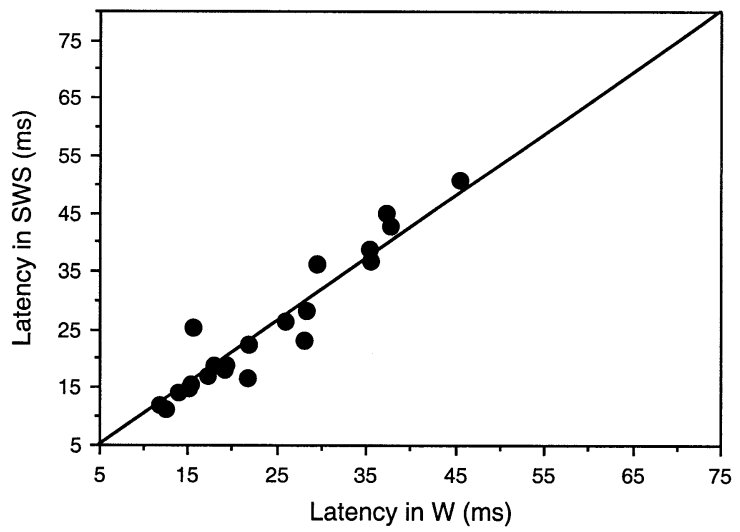

FIG. 6. Changes in receptive field (RF) size and in responses latency during SWS as a function of the changes in the mean evoked activity. (A) The RF size (quantified here by the square root transform; see Materials and methods) was smaller in SWS than in waking for the cells whose evoked activity was decreased. In most of the cases, it was larger when the evoked response was increased. It was smaller, larger or unchanged when the evoked response was not modified. (B) The response latency in SWS was increased for most of the cells whose evoked activity was decreased, whereas it was decreased for the cells whose evoked activity was increased. The responses latency was unchanged when the evoked activity was not modified.

\section{Changes observed during PS}

The scattergrams of Fig. 9 show the data obtained for the 12 cells tested during PS and waking. As it can be seen, no dominant effect appeared for any of the quantified parameters. As a consequence, none of the statistical comparisons performed (using either parametric or nonparametric tests) revealed any significant differences between the two states. For example, no overall significant difference existed for the spontaneous and evoked activities. Still, the statistics performed individually on each cell revealed that many cells exhibited significant changes in firing rate from waking to PS: spontaneous activity was significantly increased for six cells and decreased for two cells; the evoked activity was increased for five cells and decreased for three cells. An example of decreased evoked responses in PS can be seen in Fig. 3; an example of increased evoked responses is presented in Fig. 10 .

Similarly, there was no overall modification for the selectivity index (mean values: 55.5 in waking vs. 61 in PS), the RF size (with the square root transform: 0.93 vs. 0.96 ; with the $\mathrm{Q}_{40 \mathrm{~dB}}$ : 3.13 vs. $2.99)$, the responses latency $(22.5$ vs. $24.7 \mathrm{~ms})$ or the latency variability (11.2 vs. $14.3 \mathrm{~ms})$. However, examination of individual data revealed that these different parameters could be affected during PS. For example, the RF size was reduced in PS for the cells showing decreased evoked responses (see the example presented in Fig. 3) whereas it was enlarged for the cells showing increased evoked responses (see Fig. 10).

Lastly, for most of the cells the BI values were lower in PS than in waking, both during spontaneous activity (mean values: 4.8 in PS vs. 9.1 in waking) and during tone presentations (30.6 vs. 40.2). Here again, however, the differences between the two states were not statistically significant.

\section{Discussion}

At a first look, the present data seem to indicate that basic functional properties of auditory cortex neurons are unaffected across vigilance 


\section{A. During Spontaneous Activity}

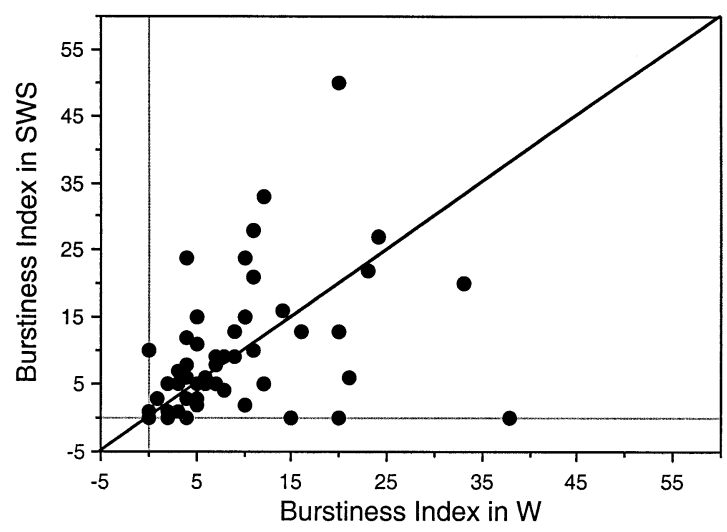

B. During Evoked Activity

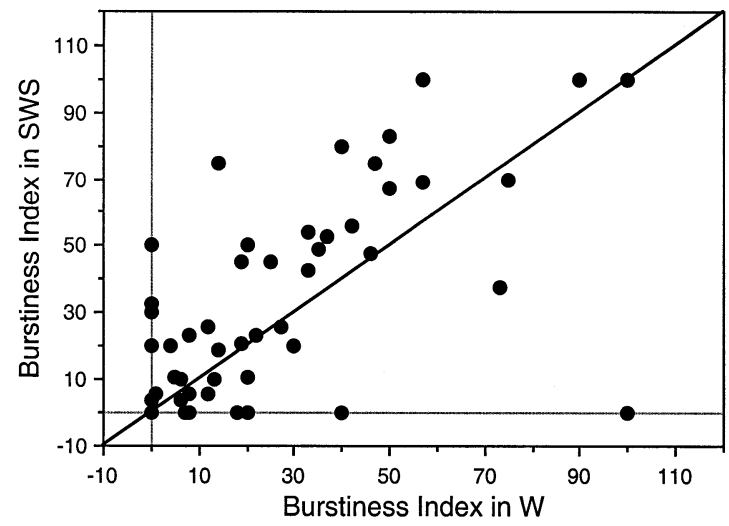

FIG. 7. Effect of the vigilance state on the firing mode estimated by the 'burstiness index'. (A) During spontaneous activity, increases, decreases or no changes in the value of the burstiness index (BI; see Materials and methods for definition) were observed during SWS. On the whole cell population, there was no significant difference between SWS and waking. (B) In contrast, during evoked activity, for most of the cells the BI value was higher during SWS than during waking; the difference between the two states was significant.

states: overall, the response latencies, the frequency selectivity and the RF size were not significantly changed in SWS relative to waking. However, as discussed below, this 'average picture' masks the fact that cortical neurons behaved differently during SWS. The small number of cells recorded during PS precludes strong conclusions, but the data suggest that cortical cells also showed heterogeneous changes during PS.

\section{Comparison with data obtained in undrugged animals}

An obvious question is whether the sleep-related changes observed at the cortical level could be predicted by changes occurring downstream. Using exactly the same protocol and the same quantifications, we previously described changes in RF properties of auditory thalamus neurons which differed from those presented here. The decreased evoked responses of thalamic neurons during SWS were accompanied by an increase in frequency selectivity and a decrease in RF size (Edeline et al., 2000). In contrast, though the average evoked activity of cortical cells was also decreased, curiously, the average frequency selectivity and RF size were not altered. Several factors can account for these discordances between our thalamic and cortical data. The first one is that the number of cortical cells tested $(n=56)$ was smaller than the one allowing the description of our thalamic results $(n=102)$. However, arguing against this explanation, many comparisons in our previous study were based on a subpopulation of 53 cells (namely, neurons that were recorded during all three states of vigilance), and this subpopulation exhibited exactly the same changes in SWS as the whole population of 102 cells. The second possibility is that the proportions of cells showing decreased, increased or unchanged evoked responses during SWS differed between the thalamic and the cortical level. Indeed, we observed here as well as in previous studies (Manunta \& Edeline, 1997, 1999; Edeline et al., 2000) that the frequency selectivity and the RF size varied as a function of the changes in evoked activity. The distributions of cells displaying decreased, increased or unchanged evoked responses within the population of 56 cortical cells and within the subpopulation of 53 thalamic cells of our previous study (see Table 3 in Edeline et al., 2000) were compared with a $\chi^{2}$ test. It appeared that these distributions did significantly differ $(P=0.019)$. Fewer cortical cells $(27 / 56,48 \%)$ than thalamic cells $(37 / 53,70 \%)$ showed decreased evoked responses in SWS; more cortical than thalamic cells showed unchanged (38\% vs. $28 \%)$ or increased (14\% vs. $2 \%)$ responses. The third possibility is that the magnitude of changes in evoked responses displayed by cortical cells was less pronounced than that displayed by thalamic cells. This was not the case. When we focused on the 27 cortical cells and on the 37 thalamic cells whose evoked responses were depressed in SWS, it appeared that these cells manifested a similar lowering of responses from waking to SWS (cortical cells: from $19.32 \mathrm{spikes} / \mathrm{s}$ in waking to 10.08 spikes/s in SWS; thalamic cells: from 19.0 to 7.98 spikes $/ \mathrm{s} ; F_{1,62}=0.492, P=0.485$, for Structure-State interaction).

Thus, the lack of overall modifications observed here during SWS for the frequency selectivity and the RF size most probably resulted from the heterogeneous response changes that existed among cortical cells. This heterogeneity was not observed at the thalamic level. These conclusions totally agree with the observations made by Livingstone \& Hubel (1981) in the visual system. These authors stressed the fact that visual cortex neurons varied greatly from one to the next in the degree to which they were influenced by changes in arousal level, even mentioning that marked differences in responses could exist between two cells simultaneously recorded from the same electrode. They also pointed out that the effects produced by arousal were less variable and much stronger at the thalamic than at the cortical level. Arrest of EEG slow waves was associated with consistent elevations in evoked activity of geniculate cells $(n=14)$, which contrasted with the modest effects on cortical neurons, most of which showed only a small increase in response. Another similarity exists between the present results and those reported by Livingstone $\&$ Hubel (1981). Though their study is currently cited as the one providing evidence for an enhancement of cells' selectivity on natural arousal, it is worth emphasizing that this effect was only observed for a few cells: for most of visual cortex cells, the direction or orientation selectivity was unchanged on arousal, which is in agreement with the lack of global change in frequency selectivity observed here during SWS. Thus, the discrepancies between the results obtained in the visual cortex by Livingstone and Hubel and those we had previously obtained in the auditory thalamus seem to mainly reflect differences in state-dependent changes occurring at the cortical and thalamic levels, rather than differences between the visual and auditory systems.

Further evidence supports the notion that sleep-related changes at the cortical level do not merely reflect changes occurring downstream. It was recently reported that responses to a single tone 


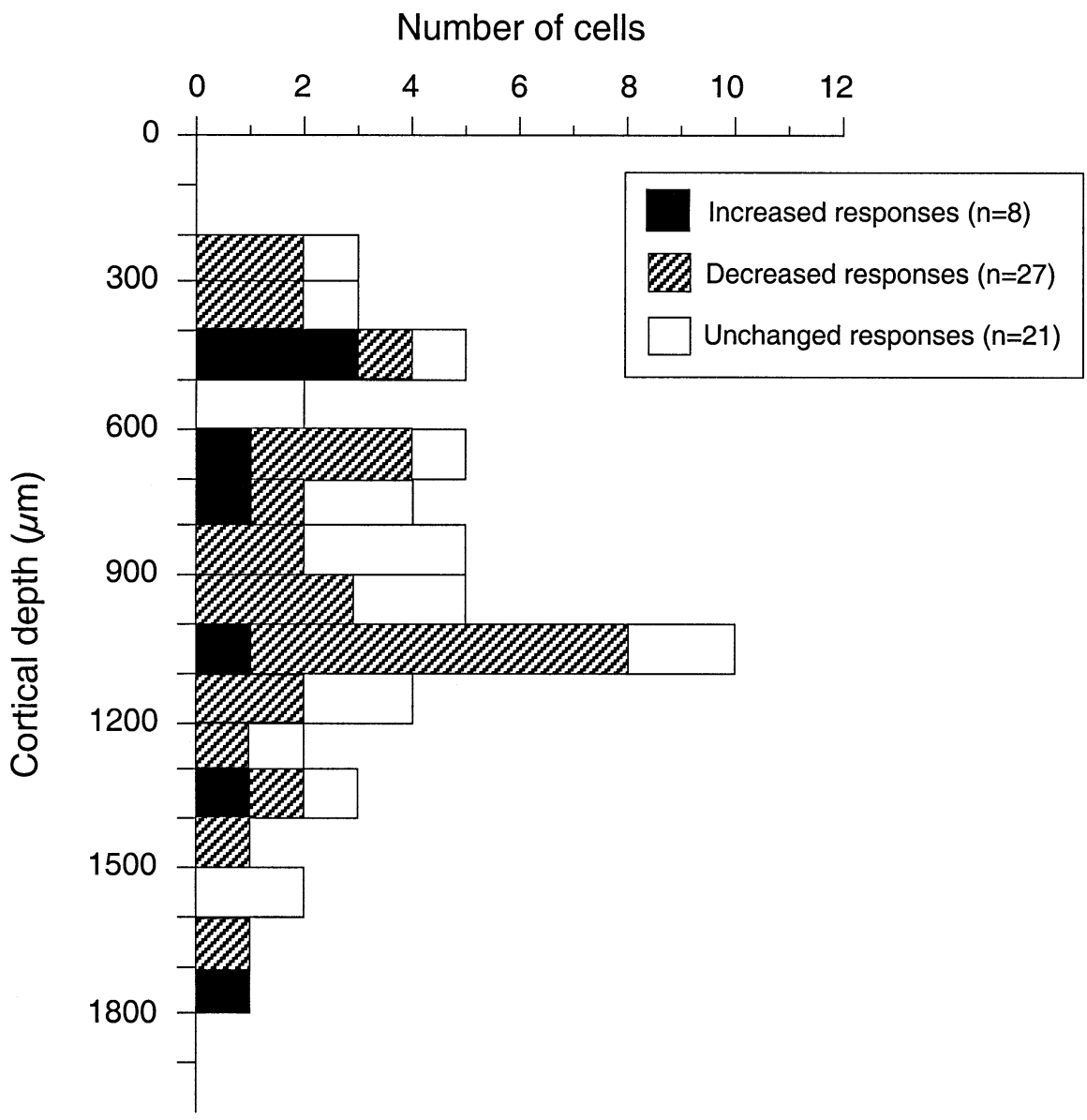

FIG. 8. Changes in evoked activity during SWS as a function of the cortical depth.The depth of each cell recorded during SWS and waking was plotted, and the data were split according to the changes in evoked activity observed during SWS. The distributions of cells showing increased, decreased or unchanged evoked responses were not different. frequency were modified for only $37 \%$ of auditory cortex cells during SWS: $27 \%$ showed decreased evoked responses and 10\% showed increased responses (Pena et al., 1999). It is noteworthy that this percentage of changes is the lowest percentage found by the same laboratory within the central auditory system: changes in responses during SWS were found for $65 \%$ of cells in the inferior colliculus (Pedemonte et al., 1994), $80.6 \%$ of cells in the lateral superior olive (Morales-Cobas et al., 1995) and $76.2 \%$ of cells in the cochlear nucleus (Pena et al., 1992). These authors did not test the responsiveness of auditory thalamus neurons.

\section{Comparison with data obtained in anaesthetized animals}

Several studies have used anaesthetized preparations to assess statedependent modulation of sensory processing. Recently, direct comparisons of the response characteristics observed for the same auditory cortex cells in the awake and anaesthetized state showed a systematic decrease of the RF sizes under anaesthesia (Gaese \& Ostwald, 2001). Another strategy that has long been used is to record neuronal activity during various depths of anaesthesia or during spontaneous fluctuations of the EEG in anaesthetized preparations. In the primary somatosensory cortex, decreases in spontaneous activity, in evoked responses and in RF size were observed with increasing anaesthetic depth (Duncan et al., 1982; Armstrong-James \& George, 1988; Diamond et al., 1992). Recordings from the auditory thalamus and cortex of lightly anaesthetized cats also showed that deepening the level of anaesthesia by various agents led to depression of the evoked responses, increase in the frequency selectivity and reduction in the RF size (Zurita et al., 1994). In line with these data, the width of the frequency tuning of auditory cortex neurons was found to be smaller when the responses were composed of bursts than when they were composed of isolated spikes, thus suggesting that bursting activity promotes smaller RFs (Eggermont \& Smith, 1996).

All these effects are clearly at variance with those recently described in the visual cortex of anaesthetized cats. Wörgötter et al. (1998) reported that the RFs of visual cortex neurons were wider during periods of synchronized EEG than during periods of desynchronized EEG. From the examples provided in this study, it appears that the RF enlargement could occur with either a decrease or an increase in visual responses which, as mentioned by the authors, did not seem to be correlated to the EEG. Still, data obtained by the same laboratory showed that visual responses of thalamic neurons were strongly attenuated during periods of synchronized EEG compared with periods of nonsynchronized EEG, an attenuation due to a suppression of the tonic component of the response (Funke \& Eysel, 1992; Li et al., 1999). To account for these rather paradoxical results, Wörgötter et al. (1998) proposed a model according to which bursts of thalamic activity during synchronized-EEG periods would allow strong temporal summation at the cortical target cells, resulting in wide and less specific cortical RFs. To what extent this assumption can be applied to natural SWS is questionable. Even if bursting is more common during SWS than during wakefulness, tonic firing predominates during SWS in the lateral geniculate nucleus (Ramcharan et al., 2000). Several studies have even revealed that a non-negligible proportion of lateral geniculate neurons never bursted during SWS (37\% in McCarley et al., 1983; 17\% in Weyand et al., 2001). In addition, a large fraction of bursting originated from a small 

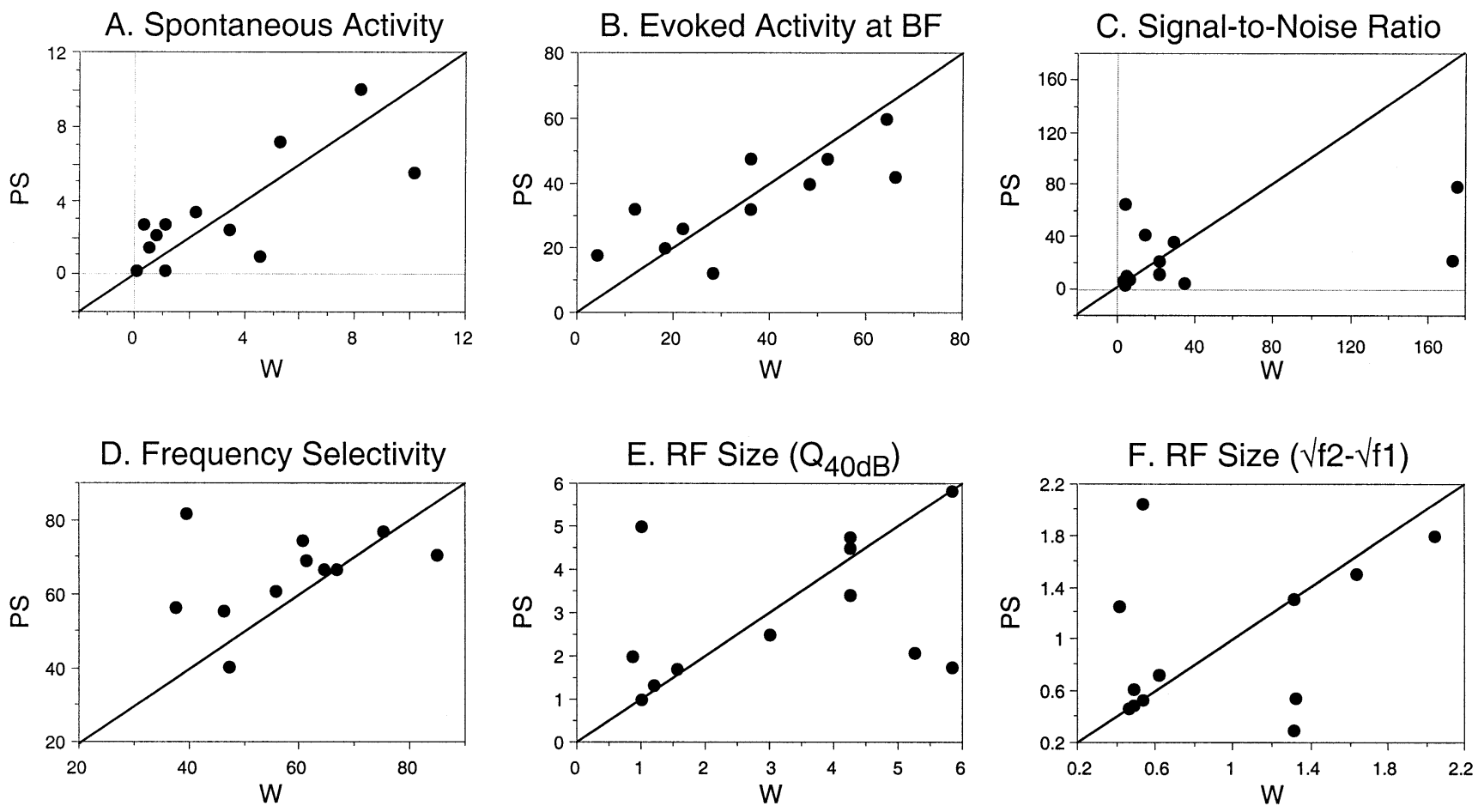

FIG. 9. Scattergrams of data obtained for the 12 cells tested during waking and PS. Whatever the parameter considered, no significant difference was found between the values obtained during PS and those obtained during waking (lowest $P$-value, 0.25 , for the frequency selectivity). Abbreviations as in Fig. 1.

number of cells: $>50 \%$ of the bursts were generated by $14 \%$ of the cells in the study of Weyand et al. (2001).

Such discordances indicate that despite some apparent resemblances in the EEG, it would be unwise to simply assimilate the natural sleep and waking states to the EEG-synchronized and EEGdesynchronized periods occurring under anaesthesia. General anaesthestics can promote a state of synchronized EEG by acting via various mechanisms (for example, by reinforcing GABAergic transmission, by activating $\mathrm{K}^{+}$channels or by blocking NMDA receptors). Each of these mechanisms will have different consequences on the spontaneous and evoked responses, the burstiness of the cells and the RF size (see, for example, Dougherty et al., 1997). None of these mechanisms can pretend to mimic the complex and multiple factors that controlled the EEG-synchronized state of SWS (see Lydic \& Baghdoyan, 1999). Therefore, caution has to be exerted in considering that RF changes observed in anaesthetized preparations might mimic those occurring across the natural states of vigilance. To take a last example illustrating the fact that apparent resemblances in the EEG can be deceptive, both waking and PS are characterized by a desynchronized EEG although they constitute fundamentally different behavioural states.

\section{Possible mechanisms}

As discussed above, the auditory messages that cortical neurons receive from thalamic cells during SWS are already modified. In most of the cases, the thalamic signals are reduced in terms of both firing rate and frequency range (Edeline et al., 2000). A priori, this should predict cortical responses for a limited frequency range, thus shrinked cortical RFs. This effect was indeed observed for half of the cells, but the other half showed unchanged or, in a few cases, enlarged RF size.

Several factors can potentially account for this heterogeneity of response changes among cortical cells. Recently, Steriade and collaborators (Timofeev et al., 2001) have definitely established that cortical neurons show a much larger dispersion of the membrane potential during SWS (from -71.7 to $-62.1 \mathrm{mV}$ ) than during waking (around a mean of $62.5 \mathrm{mV}$ ), because of the succession of hyperpolarizing and depolarizing phases of the slow wave sleep oscillation. Whereas the cyclic and prolonged hyperpolarizations are accompanied by arrest in firing, the depolarizing phases are accompanied with firing rates equal to or even exceeding those found during waking. However, such fluctuations within the SWS state cannot account for the diversity of changes in spontaneous and evoked activities observed here, because every cell was systematically tested over a 110-s period of SWS (or of waking). Another possibility we had envisaged is that differential changes occurred in the input vs. in the output cortical layers. However, this seems unlikely because none of the observed changes was a function of the cortical depth. A third possibility could be that cortical cells with different firing patterns (McCormick et al., 1985; Gray \& McCormick, 1996; Steriade et al., 1998) display different state-dependent changes. Indeed, a recent intracellular study (Steriade et al., 2001) clearly showed that the spontaneous firing rate of these different cell types evolved differentially across the natural states of vigilance. For example, the regular spiking cells increased their firing from waking to SWS and from SWS to PS, the fast rhythmic bursting cells showed exactly the opposite pattern and the fast spiking cells exhibited the lowest firing rate during SWS and the highest one during PS. In view of their different evolution in spontaneous firing, it seems most likely that these cells also exhibit differential evolution in evoked activity during SWS. Note that the diversity in the way cortical cells behave as a function of membrane potential contrasts with the stereotyped behaviour of thalamic cells that switch from bursting to tonic mode when depolarized by a current pulse in vitro or in vivo (for a recent review, see Sherman, 2001). A last possibility to explain the heterogeneous changes we observed at the cortical level is to consider the diversity of effects than can be produced by 

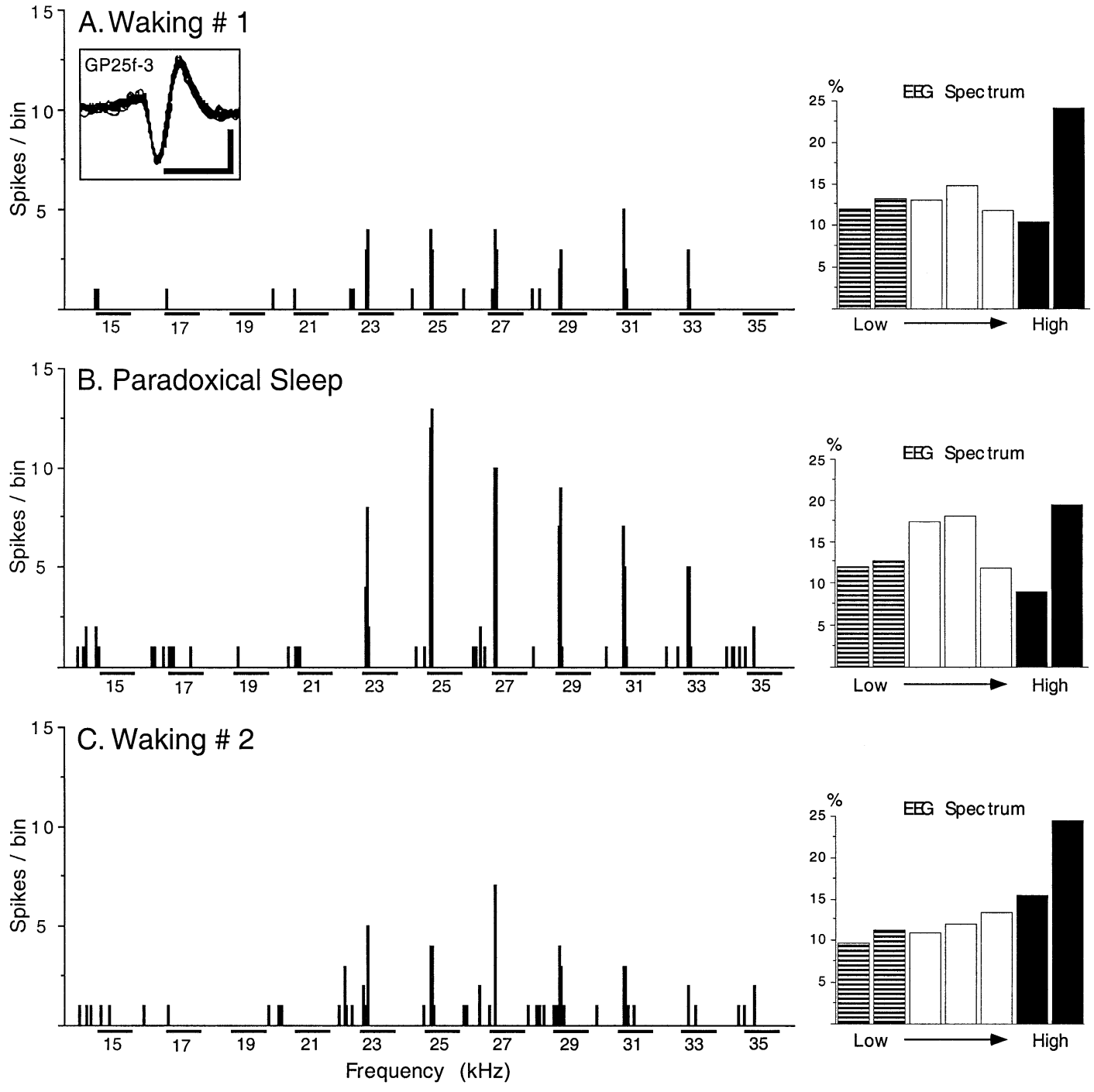

D. Evoked Activity

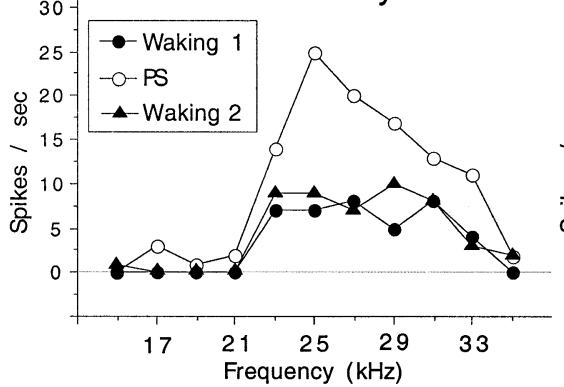

E. Spontaneous Activity

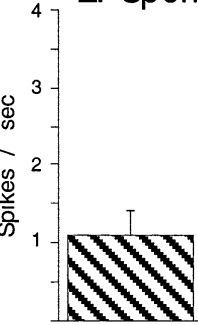

Waking 1

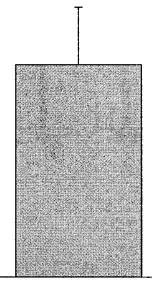

PS

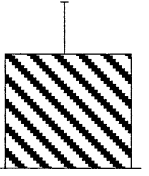

Waking 2

FIG. 10. Increases in evoked and spontaneous activities during PS. The histograms display the responses evoked at $70 \mathrm{~dB}$ in the RF of a cell (GP25f-3; scale bars, $400 \mu \mathrm{V}, 0.5 \mathrm{~ms}$ ) recorded $360 \mu \mathrm{m}$ below pia. The cell was tested successively during waking and PS, then again during waking; it was not tested during SWS. (A) During waking, evoked responses were observed from 23 to $33 \mathrm{kHz}$. (B) During PS, enhanced responses were observed for the same frequencies. (C) During the subsequent waking episode, the responses came back to their original magnitude. The quantification of the evoked (D) and spontaneous (E) activities shows the stability of the values obtained in waking and the increases that occurred during PS. Conventions as in Fig. 2.

state-dependent changes in the activity of neuromodulatory systems. For example, the release of acetylcholine (ACh) and of noradrenaline (NA) is much lower during SWS than during wakefulness (review in Steriade \& McCarley, 1990). How these decreased releases affect responsiveness of cortical neurons is difficult to estimate. Indeed, in the auditory cortex, ACh increases tone-evoked responses (Metherate \& Ashe, 1991; Hars et al., 1993; Edeline et al., 1994; Bakin \& Weinberger, 1996; Kilgard \& Merzenich, 1998) whereas NA usually decreases them (Manunta \& Edeline, 1997, 1999). In addition, a given neuromodulator, as NA, can produce excitatory or inhibitory 
effects depending on the density of alpha vs. beta receptors on the cortical cell membrane (Manunta \& Edeline, 1997). Thus, depending on the types and/or the relative density of ACh or NA receptors, the changes in neuromodulator concentrations associated with SWS could differentially affect spontaneous and evoked activities of auditory cortex neurons during SWS.

\section{Functional implications}

At a first glance, if we consider the whole cell population, cortical processing of acoustic stimuli during sleep does not seem to be fundamentally different from the one occurring during waking. However, this is clearly an oversimplication given that neurons of the auditory cortex do not behave as a unique entity: both during SWS and PS, some neurons display smaller RFs than during waking, while at the same time others display larger RFs. These changes only partially reflect those occurring at the thalamic level, thus indicating that cortical circuits process auditory information relatively independently. The nature of the 'gain' due to intracortical processing remains to be determined, but testing biologically relevant stimuli instead of pure tones may help clarify this question.

It is also important to consider that, beyond the changes occurring from wakefulness to sleep, sensory processing can also be modified within a given state of vigilance, particularly during wakefulness. For example, in the behaving monkey, the evoked responses and the frequency selectivity of auditory cortex cells were larger when the animal was performing a reaction time task than when it was not (Miller et al., 1972); moreover, in the nonperformance condition the responses were intermediate between those obtained in the performance condition and those obtained during drowsiness (Pfingst et al., 1977). Thus, for a given cell, a continuum of responsiveness seems to exist within a given state. Results obtained by manipulating the level of difficulty during attentional tasks support this view. However, as observed across vigilance states, the changes can go in both directions: increasing the attentional demand can enhance the responses and the selectivity of cortical cells (Spitzer et al., 1988), but it can also decrease the cell responsiveness (Lecas, 1995). A major challenge for future research should be to understand how the control that exerts the natural vigilance states and attentional processes on cortical circuits allows transformation of sensory information into perceptions.

\section{Abbreviations}

$\mathrm{BF}$, best frequency; BI, burstiness index; EEG, cortical electroencephalogram; FRF, frequency response function; PS, paradoxical sleep; RF, receptive field; SPL, sound pressure level; SWS, slow-wave sleep.

\section{References}

Abeles, M. \& Goldstein, M. (1972) Responses of single units in the primary auditory cortex of the cat to tones and to tone pairs. Brain Res., 42, 337352.

Armstrong-James, M. \& George, M.J. (1988) Influence of anesthesia on spontaneous activity and receptive field size of single units in rat $\mathrm{Sm} 1$ neocortex. Exp. Neurol., 99, 369-387.

Bakin, J.S. \& Weinberger, N.M. (1996) Induction of a physiological memory in the cerebral cortex by stimulation of the nucleus basalis. Proc. Natl Acad. Sci. USA, 93, 11219-11224.

Bienenstock, E.L., Cooper, L.N. \& Munro, P.W. (1982) Theory for the development of neuron selectivity: orientation specificity and binocular interaction in visual cortex. J. Neurosci., 2, 32-48.

Brugge, J.F. \& Merzenich, M.M. (1973) Responses of neurons in auditory cortex of macaque monkey to monaural and binaural stimulation. $J$. Neurophysiol., 36, 1130-1158.
Calford, M.B., Webster, W.R. \& Semple, M.M. (1983) Measurement of frequency selectivity of single neurons in the central auditory pathway. Hear. Res., 11, 395-401.

Connors, B.W. \& Gutnick, M.J. (1990) Intrinsic firing patterns of diverse neocortical neurons. Trends Neurosci., 13, 99-104.

Diamond, M.E., Armstrong-James, M. \& Ebner, F.F. (1992) Somatic sensory responses in the rostral sector of the posterior group (POm) and in the ventral posterior medial nucleus (VPM) of the rat thalamus. J. Comp. Neurol., 318, 462-476.

Dougherty, P.M., Li, Y.J., Lenz, F.A., Rowland, L. \& Mittman, S. (1997) Correlation of effects of general anesthetics on somatosensory neurons in the primate thalamus and cortical EEG power. J. Neurophysiol., 77, 13751392.

Duncan, G.H., Dreyer, D.A., McKenna, T.M. \& Whitsel, B.L. (1982) Doseand time-dependent effects of ketamine on SI neurons with cutaneous receptive fields. J. Neurophysiol., 47, 677-699.

Edeline, J.-M., Maho, C., Hars, B. \& Hennevin, E. (1994) Non-awaking basal forebrain stimulation enhances auditory cortex responsiveness during slowwave sleep. Brain Res., 636, 333-337.

Edeline, J.-M., Manunta, Y. \& Hennevin, E. (2000) Auditory thalamus neurons during sleep: changes in frequency selectivity, threshold and receptive field size. J. Neurophysiol., 84, 934-952.

Edeline, J.-M., Manunta, Y., Nodal, F.R. \& Bajo, V. (1999) Do auditory responses recorded from awake animals reflect the anatomical parcellation of the auditory thalamus? Hear. Res., 131, 135-152.

Eggermont, J.J. \& Smith, G.M. (1996) Burst-firing sharpens frequency-tuning in primary auditory cortex. Neuroreport, $7,753-757$.

Evans, E.F. (1979) Neuroleptanesthesia for the guinea pig. Arch. Otolaryngol., 105, 185-186.

Frégnac, Y., Shulz, D., Thorpe, S. \& Bienenstock, E. (1992) Cellular analogs of visual cortical epigenesis. I. Plasticity of orientation selectivity. $J$. Neurosci., 12, 1280-1300.

Funke, K. \& Eysel, U.T. (1992) EEG-dependent modulation of responses dynamics of cat dLGN relay cells and the contribution of corticogeniculate feedback. Brain Res., 573, 217-227.

Gaese, B.H. \& Ostwald, J. (2001) Anesthesia changes frequency tuning of neurons in the rat primary auditory cortex. J. Neurophysiol., 86, 1062-1066.

Gray, C.M. \& McCormick, D.A. (1996) Chaterring cells: superficial pyramidal neurons contributing to the generation of synchronous oscillations in the visual cortex. Science, 274, 109-113.

Guido, W., Lu, S.M. \& Sherman, S.M. (1992) Relative contributions of burst and tonic responses to the receptive field properties of lateral geniculate neurons in the cat. J. Neurophysiol., 68, 2199-2211.

Hars, B., Maho, C., Edeline, J.-M. \& Hennevin, E. (1993) Basal forebrain stimulation facilitates tone-evoked responses in the auditory cortex of awake rat. Neuroscience, 56, 61-74.

Kiang, N.Y.S., Watanabe, T., Thomas, E.C. \& Clark, L.F. (1965). Discharge Patterns of Single Fibers in the Cat's Auditory Nerve. MIT Press, Cambridge, MA.

Kilgard, M.P. \& Merzenich, M.M. (1998) Cortical map reorganization enabled by nucleus basalis activity. Science, 279, 1714-1718.

Lecas, J.C. (1995) Prefrontal neurones sensitive to increased visual attention in the monkey. Neuroreport, 7, 305-309.

Li, B., Funke, K., Worgotter, F. \& Eysel, U.T. (1999) Correlated variations in EEG pattern and visual responsiveness of cat lateral geniculate relay cells. J. Physiol. (Lond.), 514, 857-874.

Livingstone, M.S. \& Hubel, D.H. (1981) Effects of sleep and arousal on the processing of visual information in the cat. Nature, 291, 554-561.

Lu, S.M., Guido, W. \& Sherman, S.M. (1992) Effects of membrane voltage on receptive field properties of lateral geniculate neurons in the cat: contributions of the low-threshold $\mathrm{Ca}^{2+}$ conductance. J. Neurophysiol., 68, 2185-2198.

Lydic, R. \& Baghdoyan, H.A. (1999). Handbook of Behavioral State Control: Cellular and Molecular Mechanisms. CRC Press, Boca Raton.

Manunta, Y. \& Edeline, J.-M. (1997) Effects of noradrenaline on frequency tuning of rat auditory cortex neurons. Eur. J. Neurosci., 9, 833-847.

Manunta, Y. \& Edeline, J.-M. (1999) Effects of norepinephrine on frequency tuning of auditory cortex neurons during wakefulness and slow-wave sleep. Eur. J. Neurosci., 11, 2134-2150.

McCarley, R.W., Benoit, O. \& Barrionuevo, G. (1983) Lateral geniculate nucleus unitary discharge in sleep and waking: state- and rate-specific aspects. J. Neurophysiol., 50, 798-818.

McCormick, D.A., Connors, B.W., Lighthall, J.W. \& Prince, D.A. (1985) Comparative electrophysiology of pyramidal and sparsely spiny stellate neurons of the cortex. J. Neurophysiol., 54, 782-806. 
Metherate, R. \& Ashe, J.H. (1991) Basal forebrain stimulation modifies auditory cortex responsiveness by an action at muscarinic receptors. Brain Res., 559, 163-167.

Miller, J.M., Sutton, D., Pfingst, B., Ryan, A., Beaton, R. \& Gourevitch, G. (1972) Single cell activity in the auditory cortex of rhesus monkeys: behavioral dependency. Science, 177, 449-451.

Morales-Cobas, G., Ferreira, M.I. \& Velluti, R.A. (1995) Firing of inferior colliculus neurons in response to low-frequency sound stimulation during sleep and waking. J. Sleep Res., 4, 242-251.

Mukherjee, P. \& Kaplan, E. (1995) Dynamic of neurons in the cat lateral geniculate nucleus: in vivo electrophysiology and computational modeling. J. Neurophysiol., 74, 1222-1243.

Pedemonte, M., Pena, J.L., Morales-Cobas, G. \& Velluti, R.A. (1994) Effects of sleep on the response of single cells in the lateral superior olive. Arch. Ital. Biol., 132, 165-178.

Pena, J.L., Pedemonte, M., Ribeiro, M.F. \& Velluti, R. (1992) Single unit activity in the guinea-pig cochlear nucleus during sleep and wakefulness. Arch. Ital. Biol., 130, 179-189.

Pena, J.L., Pérez-Perera, P.L., Bouvier, M. \& Velluti, R.A. (1999) Sleep and wakefulness modulation of the neuronal firing in the auditory cortex of the guinea pig. Brain Res., 816, 463-470.

Pfingst, B.E., O'Connor, T.A. \& Miller, J.M. (1977) Response plasticity of neurons in auditory cortex of the rhesus monkey. Exp. Brain Res., 29, 393 404.

Ramcharan, E.J., Gnadt, J.W. \& Sherman, S.M. (2000) Burst and tonic firing in thalamic cells of unanesthetized, behaving monkeys. Vis. Neurosci., 17, $55-62$.

Recanzone, G.H. (2000) Response profiles of auditory cortical neurons to tones and noise in behaving macaque monkeys. Hear. Res., 150, 104118.

Recanzone, G.H., Guard, D.C. \& Phan, M.L. (2000) Frequency and intensity response properties of single neurons in the auditory cortex of the behaving macaque monkey. J. Neurophysiol., 83, 2315-2331.

Redies, H., Sieben, U. \& Creutzfeldt, O.D. (1989) Functional subdivisions in the auditory cortex of the guinea pig. J. Comp. Neurol., 282, 473-488.

Schreiner, C.E. \& Mendelson, J.R. (1990) Functional topography of cat primary cortex: distribution of integrated excitation. J. Neurophysiol., 64 , $1442-1459$.

Sherman, S.M. (2001) Tonic and burst firing: dual modes of thalamocortical relay. Trends Neurosci, 24, 122-126.

Spitzer, H., Desimone, R. \& Moran, J. (1988) Increased attention enhances both behavioral and neuronal performance. Science, 240, 338-340.

Steriade, M. \& McCarley, R.W. (1990). Brainstem Control. of Wakefulness and Sleep. Plenum Press, New York.

Steriade, M., Timofeev, I., Durmuller, N. \& Grenier, F. (1998) Dynamic properties of corticothalamic neurons and local cortical interneurons generating fast rhythmic $(30-40 \mathrm{~Hz})$ spike bursts. J. Neurophysiol., 79 , $483-490$.

Steriade, M., Timofeev, I. \& Grenier, F. (2001) Natural waking and sleep states: a view from inside neocortical neurons. J. Neurophysiol., 85, 19691985.

Timofeev, I., Grenier, F. \& Steriade, M. (2001) Disfacilitation and active inhibition in the neocortex during the natural sleep-wake cycle: an intracellular study. Proc. Natl Acad. Sci. USA, 98, 1924-1929.

Wallace, M.N., Rutkowski, R.G. \& Palmer, A.R. (2000) Identification and localisation of auditory areas in guinea pig cortex. Exp. Brain Res., 132, $445-456$.

Weyand, T.G., Boudreaux, M. \& Guido, W. (2001) Burst and tonic response modes in thalamic neurons during sleep and wakefulness. J. Neurophysiol., 85, 1107-1118.

Whitfield, I.C. (1968) The medial geniculate body of the cat. J. Sound Vib., 8, $108-117$.

Whitfield, I.C. \& Purser, D. (1972) Microelectrode study of the medial geniculate body in unanaesthetized free-moving cats. Brain Behav. Evol., 6, 311-322.

Wörgötter, F., Suder, K., Zhao, Y., Kerscher, N., Eysel, U.T. \& Funke, K. (1998) State-dependent receptive-field restructuring in the visual cortex. Nature, 396, 165-168.

Zurita, P., Villa, A.E.P., deRibaupierre, Y., deRibaupierre, F. \& Rouiller, E.M. (1994) Changes of single unit activity in the cat's auditory thalamus and cortex associated to different anesthetic conditions. Neurosci. Res., 19, 303 316. 